\title{
Documentation of INL's In Situ Oil Shale Retorting Water Usage System Dynamics Model
}

Earl D. Mattson

Larry Hull

December 2012

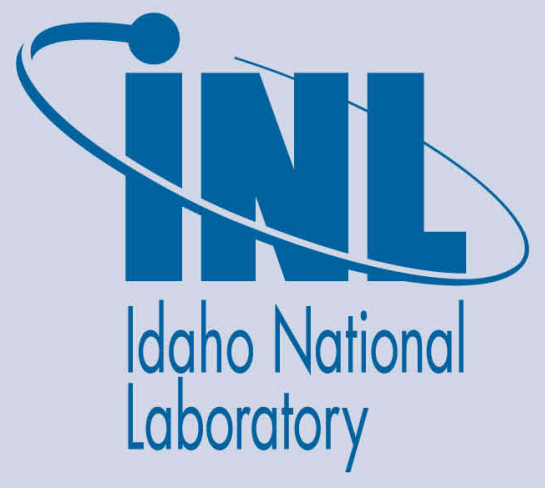

The INL is a U.S. Department of Energy National Laboratory operated by Battelle Energy Alliance 


\title{
Documentation of INL's In Situ Oil Shale Retorting Water Usage System Dynamics Model
}

\author{
Earl D. Mattson \\ Larry Hull
}

December 2012

\begin{abstract}
Idaho National Laboratory
Idaho Falls, Idaho 83415
\end{abstract}

http://www.inl.gov

\section{Prepared for}

Battelle Memorial Institute, Inc. and for the

U.S. Department of Energy

Under DOE Idaho Operations Office

Contract DE-AC07-05ID14517 


\section{DISCLAIMER}

This information was prepared as an account of work sponsored by an agency of the U.S. Government. Neither the U.S. Government nor any agency thereof, nor any of their employees, makes any warranty, expressed or implied, or assumes any legal liability or responsibility for the accuracy, completeness, or usefulness, of any information, apparatus, product, or process disclosed, or represents that its use would not infringe privately owned rights. References herein to any specific commercial product, process, or service by trade name, trade mark, manufacturer, or otherwise, does not necessarily constitute or imply its endorsement, recommendation, or favoring by the U.S. Government or any agency thereof. The views and opinions of authors expressed herein do not necessarily state or reflect those of the U.S. Government or any agency thereof. 


\section{EXECUTIVE SUMMARY}

A system dynamic model was construction to evaluate the water balance for in-situ oil shale conversion. The model is based on a systems dynamics approach and uses the Powersim Studio 9 ${ }^{\mathrm{TM}}$ software package. Three phases of an in situ retort were consider; a construction phase primarily accounts for water needed for drilling and water produced during dewatering, an operation phase includes the production of water from the retorting process, and a remediation phase water to remove heat and solutes from the subsurface as well as return the ground surface to its natural state. Throughout these three phases, the water is consumed and produced. Consumption is account for through the drill process, dust control, returning the ground water to its initial level and make up water losses during the remedial flushing of the retort zone. Production of water is through the dewatering of the retort zone, and during chemical pyrolysis reaction of the kerogen conversion. The document discusses each of the three phases used in the model. 


\section{CONTENTS}

EXECUTIVE SUMMARY iv

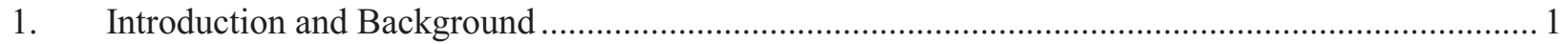

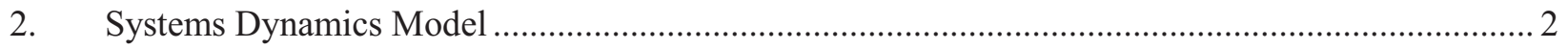

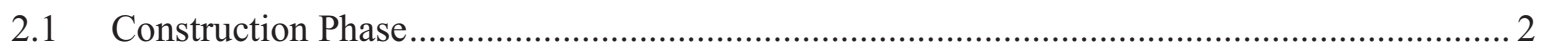

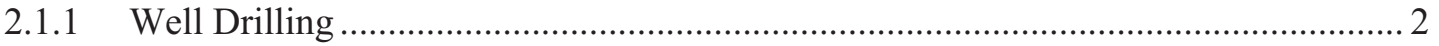

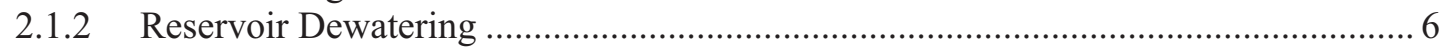

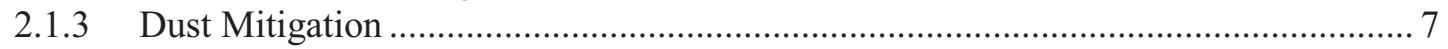

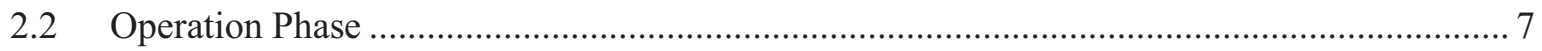

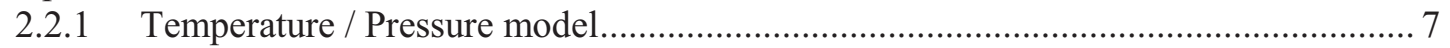

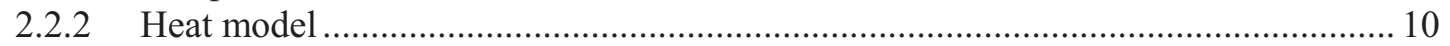

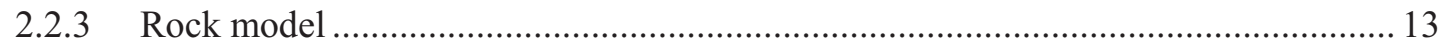

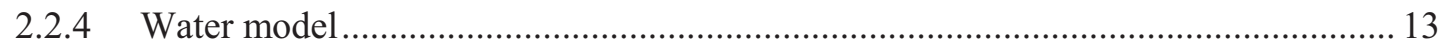

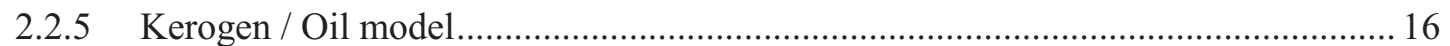

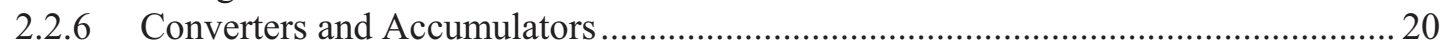

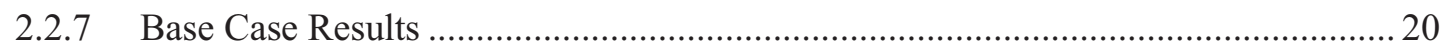

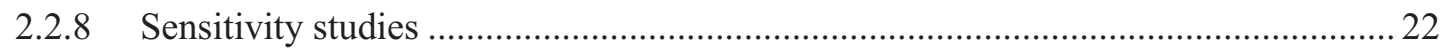

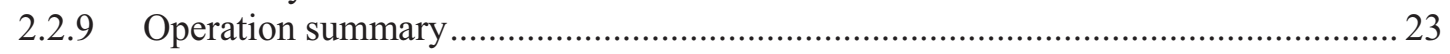

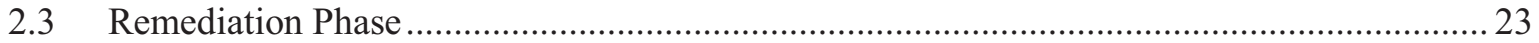

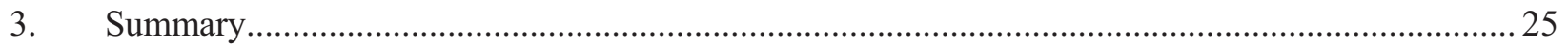

FIGURES

Figure 1. Calculation of the number of freeze wells, heated area width, length and area based on the inputted width and length of the site.

Figure 2. Calculation of the number of heater wells that are needed based on heated area calculations.

Figure 3. Calculation of the time it takes to complete each of the required wells.................................... 5

Figure 4. Calculation of the time it takes to complete all of the required wells. .......................................5

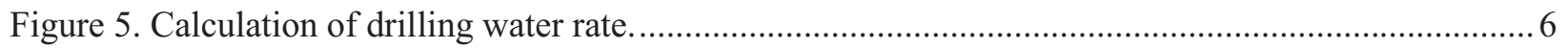

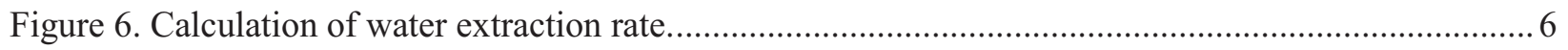

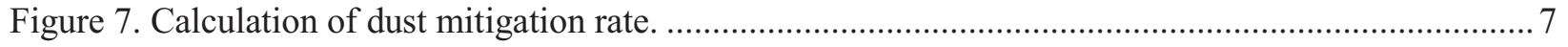

Figure 9. Stella routine to pass temperature between time steps. .......................................................... 8

Figure 9. Specific heat of water as a function of temperature below the critical point..............................9

Figure 10. Specific heat of steam as a function of temperature ........................................................ 9

Figure 11. Heat of vaporization of water as a function of temperature ................................................. 10

Figure 12. Reduced specific heat referenced to $200^{\circ} \mathrm{C}$ as a function of temperature............................... 10

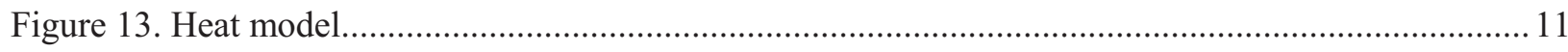


Figure 15. Vapor pressure of steam as a function of temperature used in retort model......

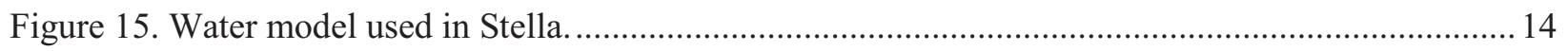

Figure 16. Function and curve to calculate boiling temperature from the hydrostatic confining pressure on the reservoir.

Figure 17. Thermal gravimetric and differential thermal gravimetric curves for a Green River oil shale specimen (Earnest 1982).

Figure 18. Mass reaction rate of kerogen as a function of retort temperature at different heating rates. Highest rates are representative of surface retorts. Lowest rate is more representative of in situ heating rates.

Figure 19. Effect of heating rate and pressure on oil yield (Burnham and Singleton 1983)......

Figure 20. Model used to calculate the pyrolysis of kerogen to products in the retort. Calculation of flows is illustrated for $\mathrm{CO}_{2}$. The other flows are calculated in the same fashion.

Figure 21. Increase in temperature and pressure with heating of the retort......

Figure 22. Distribution of kerogen and kerogen pyrolysis products as a function of time.

Figure 23. Distribution of energy (heat) in the retort during the first 1500 days.

Figure 24. Energy expended and energy recovered from the retort (joules)...... .22

Figure 25. Barrels of oil and $\mathrm{kg}$ of $\mathrm{CO} 2$ recovered from the retort. .22

Figure 26. Retort cooling as a function of injected pore volumes. 24

Figure 27. Remediation of the retort through subsurface flushing. .25

\section{TABLES}

Table 1. Compilation of kinetic rate parameters for oil shales. 18 


\section{Water Usage for In-Situ Oil Shale Retorting - A Systems Dynamics Model}

\section{Introduction and Background}

A system dynamic model was construction to evaluate the water balance for in-situ oil shale conversion. The model is based on a systems dynamics approach and uses the Powersim Studio $9^{\mathrm{TM}}$ software package. Three phases of an in situ retort were consider; a construction phase primarily accounts for water needed for drilling and water produced during dewatering, an operation phase includes the production of water from the retorting process, and a remediation phase water to remove heat and solutes from the subsurface as well as return the ground surface to its natural state. This document discusses the programming of the three phases used in INL's In situ Oil Shale Remediation.SIP Powersim model. 


\section{Systems Dynamics Model}

The water usage model is based on three phases of in the overall development of the resource: construction, operation, and remediation. In each of these development stages, water usage is very different. During the construction phase water is primarily used for drilling and for dewatering the reservoir prior to heating. During the operation phase, water will be produced from the reservoir as a result of the heating and subsequent conversion of organic matter and dehydration of minerals. During the remediation phase, water will largely be used to flush the reservoir to remove heat and potential contaminants. In addition, water will likely be used to re-establish native plant growth at the surface. These interacting processes are simulated using a systems dynamics model that solves first-order differential equations in time to simulate the evolution of a system.

The model is constructed using the Powersim Studio ${ }^{\text {TM }}$ (version 9.01), however, the energy and mass balance modules in the Operations phase were first simulated in the Stella computer code then transferred to PowerSim. Both system dynamic software packages consist of four key objects: levels (stocks), flows, auxiliaries (converters), and links (connectors) where the object names in parentheses used in Stella. Complex systems can be described by assembling these objects with proper descriptions of system characteristics.

- Levels (Stocks) -a reservoir that holds mass or heat.

- Flows - describe mass transfer between levels (stocks), or between the system and the surrounding environment.

- Auxiliary (Converters) - provide the parameters and equations used to calculate the flows or to summarize information.

- Links (Connectors) -show the flow of information through the system. What converters control what flows and how flows depend on the values of levels (stocks).

Using these four objects, a model of an in-situ retort was built.

\subsection{Construction Phase}

The three key uses/production of water during the construction phase are for drilling, reservoir dewatering and dust control. The modules used to describe water consumption/production during these activities are provided in the following sections.

\subsubsection{Well Drilling}

There are four types of wells that must be drilled to implement the oil shale development: 1) freeze wells, 2) heater wells 3) production/dewatering wells, and 4) and monitoring wells. To determine water usage we first calculate the number of required wells, then the time to complete the drilling, and finally the amount of water required for the activity. 


\subsubsection{Number of wells calculations}

The number of wells is calculated from the input desired retort dimensions, and well spacing. Freeze wells are a fairly simple calculation of the calculated perimeter divided by the sum of the desired freezer well spacing and the freeze well diameter. Figure 1 illustrates the linking of the necessary variables to the calculation. This figure also uses the buffer zone distance to calculate the heater area, width and length. These values are used to calculate the number of heater wells (Figure 2) which is the products of the truncated value of $4 *($ heated area length $) *($ heated area width $) /\left(\right.$ heater well diameter $+(2)^{0.5 *}$ heater well spacing). The number of monitoring wells is set to a fixed value (currently 3 ).

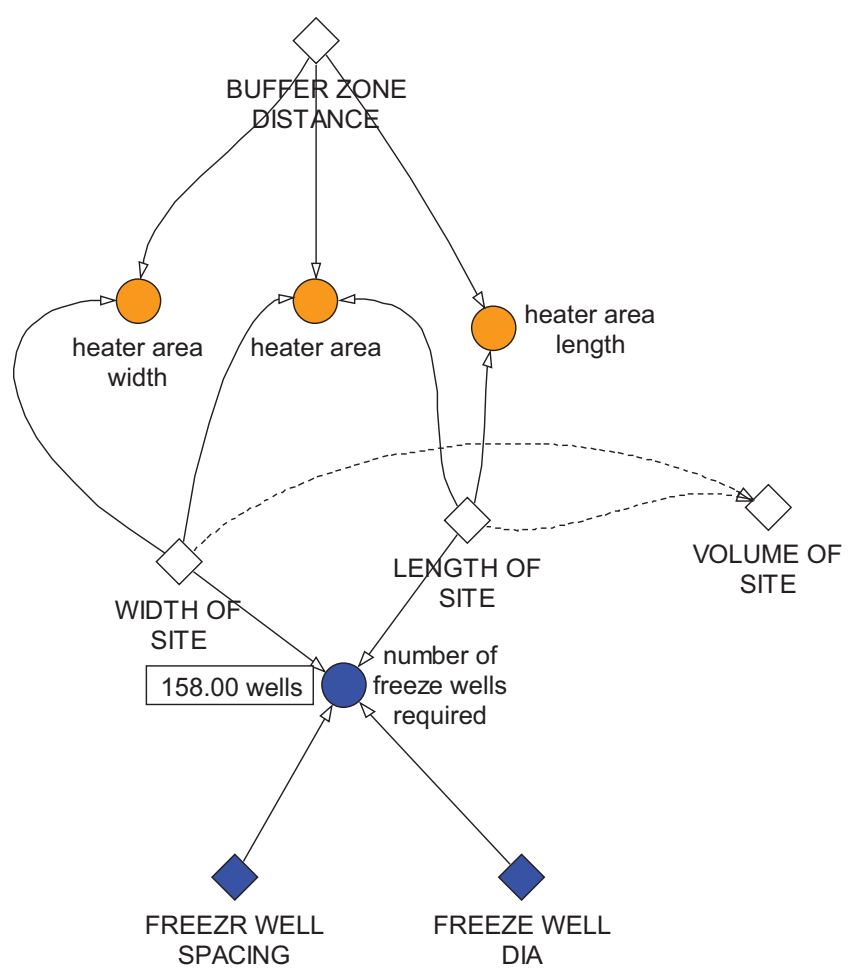

Figure 1. Calculation of the number of freeze wells, heated area width, length and area based on the inputted width and length of the site. 


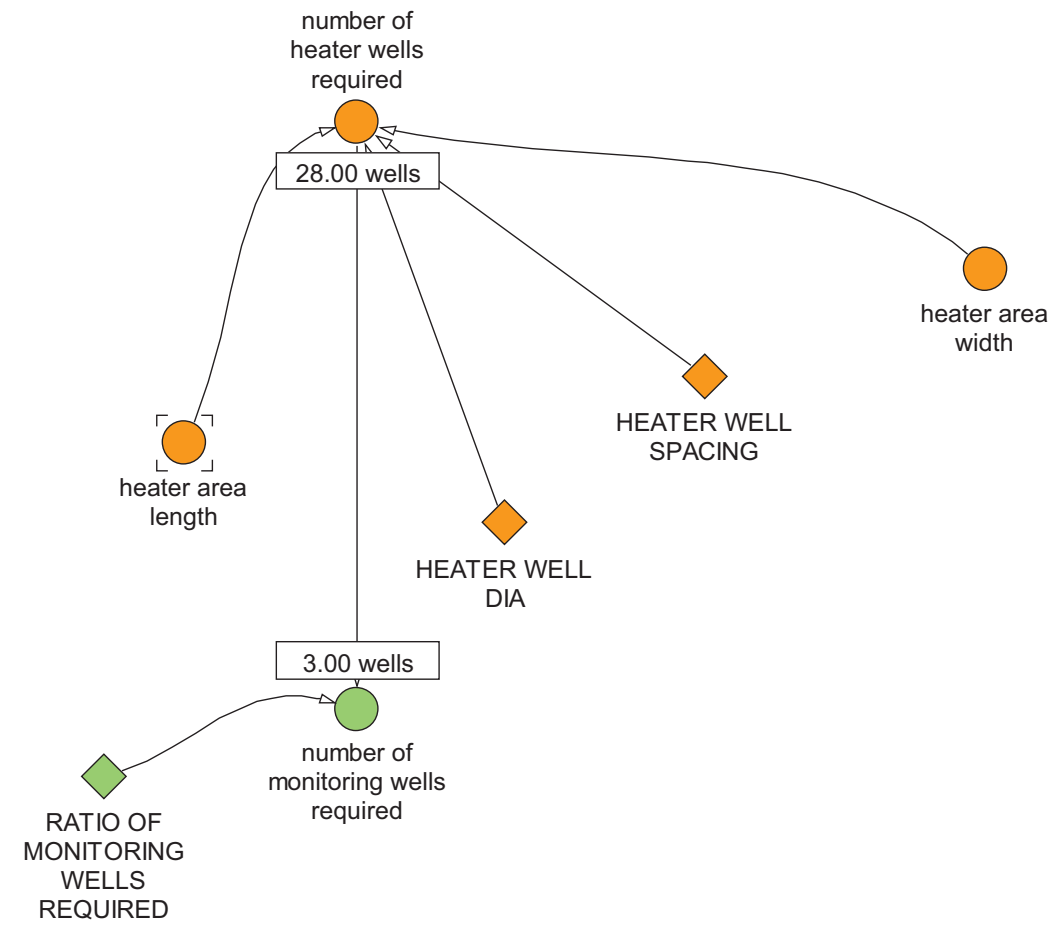

Figure 2. Calculation of the number of heater wells that are needed based on heated area calculations.

\subsubsection{Time to complete well drilling calculations}

Individual well drilling time is determined from the total depth of the retort below land surface divided by the estimated well drilling speed (Figure 3). In this case, the well drilling speed of 8 feet per hour calculated from the Shell's plan of operation statement that it required 2 months to complete 157 wells with two rigs. At this time, all wells are considered equal to the depth of the site, but the program was designed to easily change that assumption. It is also assumed that all wells have the same drilling speed regardless of use or the specific drilling rig used.

The sequence and timing of the drilling is calculated in a sequential fashion with the assumed order of that the freeze walls are first followed by the production/dewatering wells, heater wells, and finally the ground water monitoring wells. Variables used to calculate the total drilling time (Figure 4) are the number of drilling rigs and the time it takes to drill each well. All rigs are assumed to be working on the same set of wells at any time. 


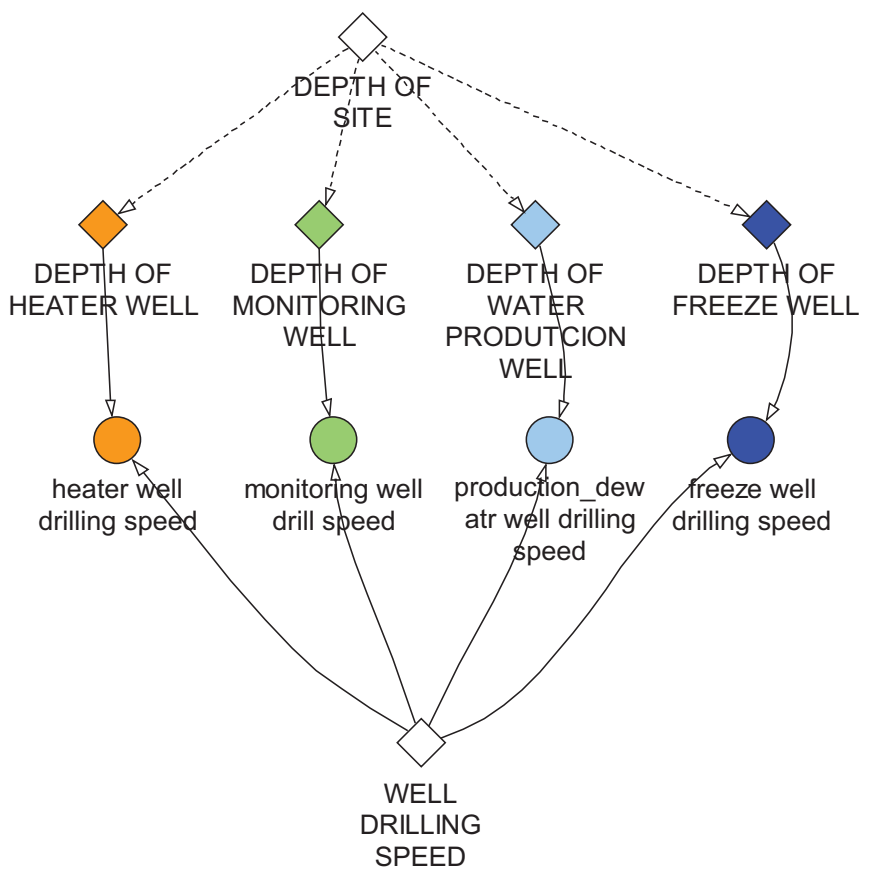

Figure 3. Calculation of the time it takes to complete each of the required wells.

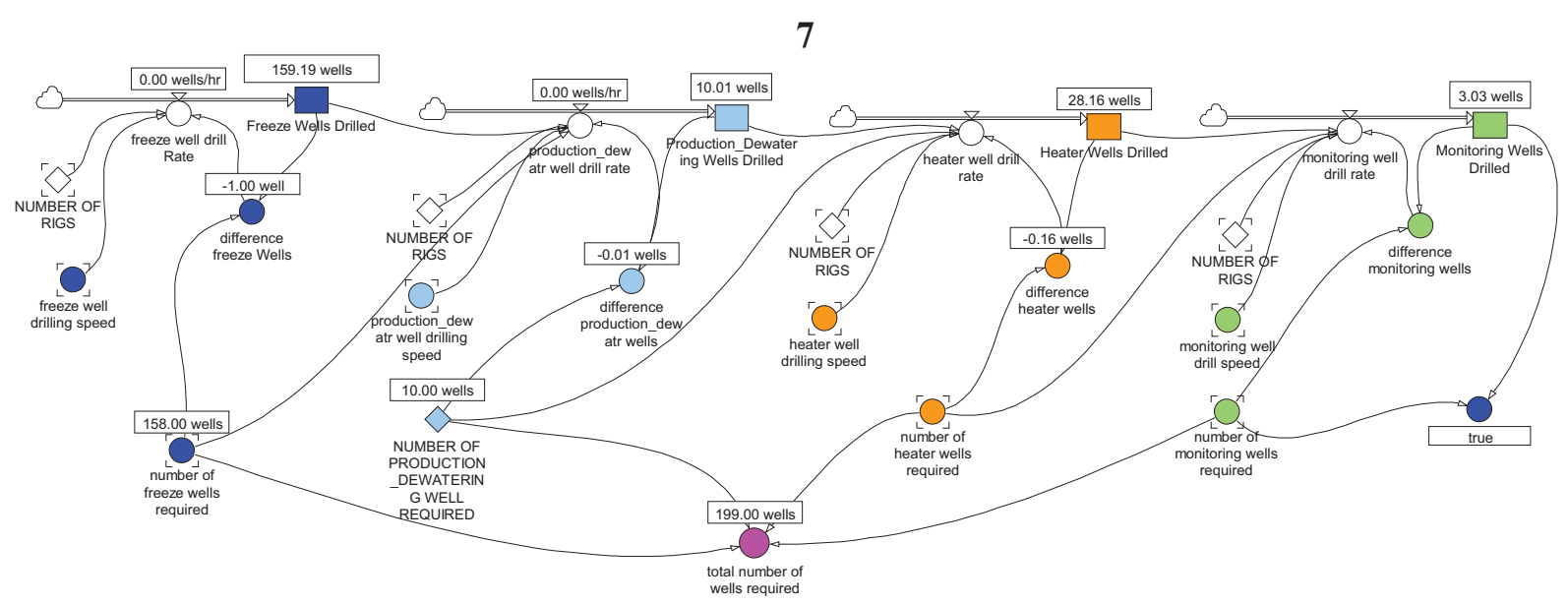

Figure 4. Calculation of the time it takes to complete all of the required wells.

\subsubsection{Water usage calculation}

Now that the number of wells needed and the time spent on each well is calculated, the amount of water required to construct these wells and the rate of water use can be determined. Drilling water use rate is calculated from the "drill lube and removal water requirement" (which can be thought as the volume of drilling fluids needed to fill the hole as the bit advances) multiplied by the drilling speed, plus the mud and seepage loss all multiplied by the recycle efficiency (Figure 5). In our case, the "drill lube and removal water requirement" is assumed to be 10 gallons per foot of drill advancement, mud loss and seepage loss. In our case, the mud loss makes up the greatest portion of the water use (about 5 times the amount of the seepage and drill bit advance combined). 


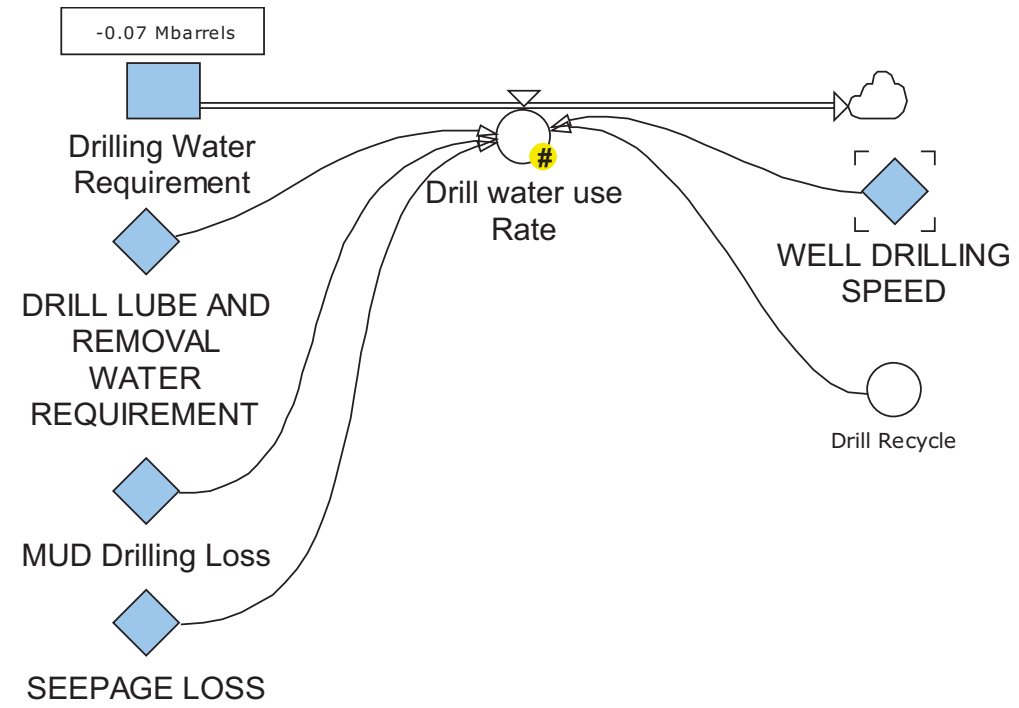

Figure 5. Calculation of drilling water rate.

\subsubsection{Reservoir Dewatering}

Prior to heating of the oil shale, water contained in the pore space of the oil shale retort volume will be removed by pumping. The volume of water to be removed is calculated from the volume of oil shale within the freeze wall and the effective porosity of the oil shale. A logic variable "dewater start" is used to initiate the dewatering of the retort volume once the freeze wells are in place. The rate of water extraction is a function of the user defined pumping rate for each well multiplied by the number of water production wells. At this time, the pumping rate is set as a constant but could be modified at a later date to be a more realistic function. The amount of water to be pumped from the retort is determined from the effective porosity multiplied by the retort volume.

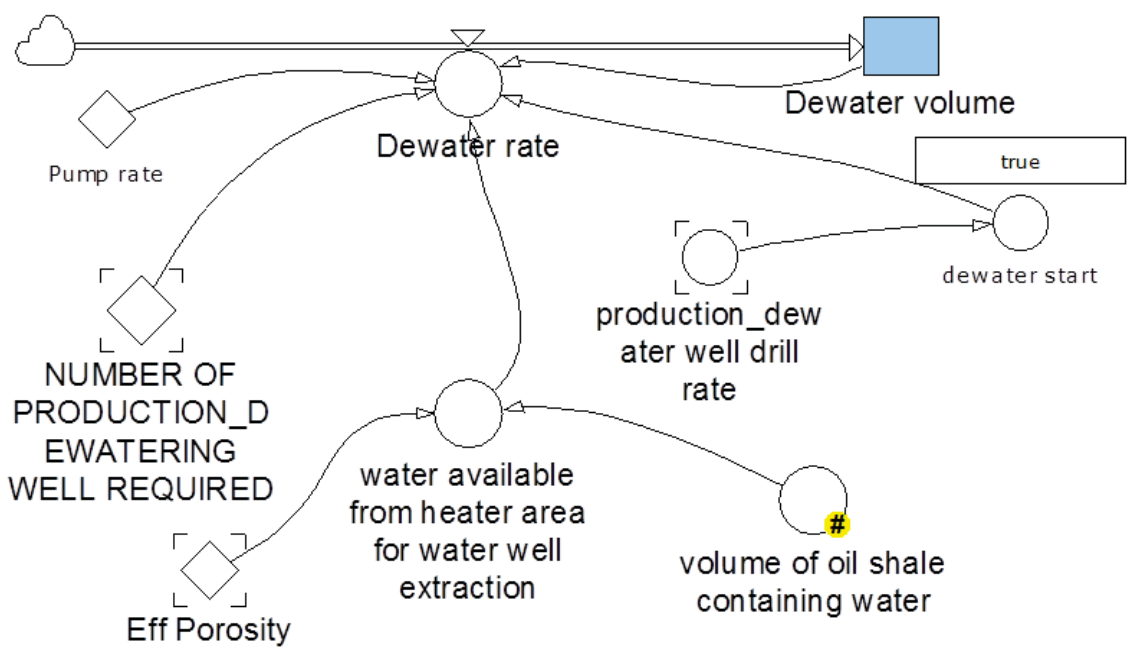

Figure 6. Calculation of water extraction rate. 


\subsubsection{Dust Mitigation}

Dust mitigation is assumed to be a constant rate of water use based on delivery of one 10,000 gallon truck delivered to the site each day (equivalent to $3 \mathrm{gpm}$ ). To determine the total amount of water during drilling, the dust mitigation rate is added to the drill water use rate for the time required to drill the wells. Total water usage during construction was 0.16 Mbarrels for this example. Main water uses were for dust mitigation and drill. Dust mitigation resulted in 0.09 Mbarrels of water required. Drilling water requirements were slight less at 0.07 Mbarrels.

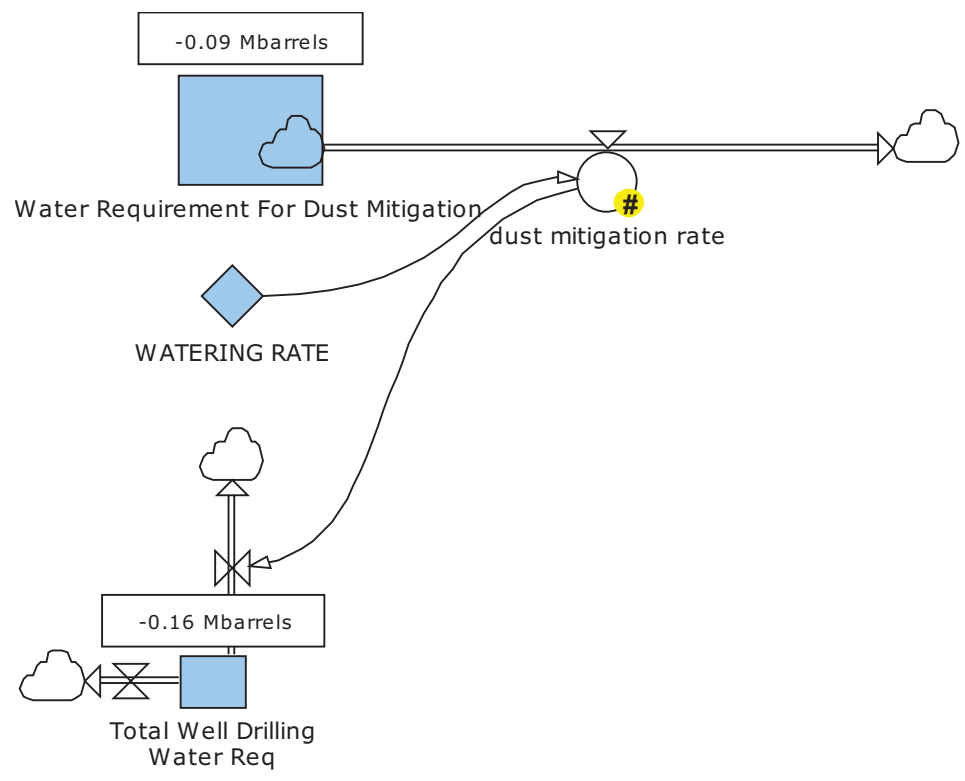

Figure 7. Calculation of dust mitigation rate.

\subsection{Operation Phase}

The second phase of oil shale development is the operation of the retort. A simple model is used to calculate the temperature increase in the retort. In-situ retort heaters are often designed in terms of their power output in kilowatts $(\mathrm{kW})$. Therefore we will input heat into the retort and calculate the temperature of the retort. The temperature will be used to update the heat capacity, phase change and reaction kinetics. The operation model will be composed of 5 components; a temperature/pressure model to update properties, a heat model, a rock model, a water model and an oil/kerogen model. The energy and mass balance modules in the were first simulated in the Stella computer code then transferred to PowerSim.

\subsubsection{Temperature / Pressure model}

The retort is assumed to start off in equilibrium with the natural geothermal gradient and the natural hydrostatic pressure head. Using the geothermal gradient of $34^{\circ} \mathrm{C} \mathrm{km}{ }^{-1}$ (Blackett 2004) and an overburden thickness of $330 \mathrm{~m}$, and a retort zone thickness of $330 \mathrm{~m}$ gives a median retort initial temperature of about $25^{\circ} \mathrm{C}$. Hydrostatic head calculated for the same depth is $3000 \mathrm{kPa}$.

The relation between temperature and heat is important for the retorting operation. There is a causal loop relation between temperature and heat through the specific heat of the components of the retort. The 
specific heat is a function of temperature, and the relation between temperature and heat depends on the specific heat. The relation between heat and temperature for a system is given by:

$$
Q_{s}=\sum_{i} m_{i} \mathbf{Q}_{i} T+v_{i}^{-}
$$

where:

$$
\begin{aligned}
\mathrm{Q}_{\mathrm{s}} & =\text { total heat in the system }(\mathrm{J}) \\
\mathrm{m}_{\mathrm{i}} & =\text { mass of component } \mathrm{i}(\mathrm{kg}) \\
\mathrm{s}_{\mathrm{i}} & =\text { specific heat of component } \mathrm{i}\left(\mathrm{J} \mathrm{kg}^{-1} \mathrm{~K}^{-1}\right) \\
\mathrm{T} & =\text { temperature of system }(\mathrm{K}) \\
\mathrm{v}_{\mathrm{i}} & =\text { heat associated with any phase changes }\left(\mathrm{J} \mathrm{kg}^{-1}\right)
\end{aligned}
$$

Equation 1 can be solved for $\mathrm{T}$, and used to calculate temperature from the total heat and the masses of components in the retort. Thus, heat is the independent variable, and temperature is the dependent variable.

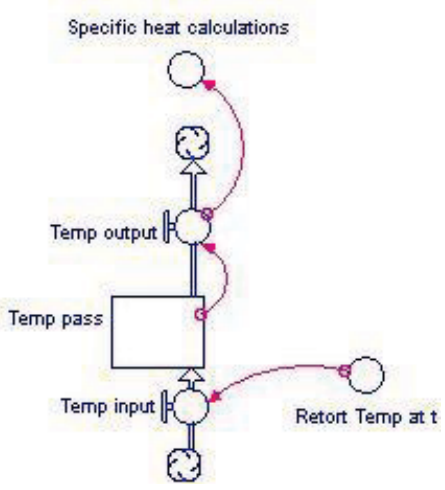

Figure 8. Stella routine to pass temperature between time steps.
The properties of water and steam as a function of temperature and pressure have been extensively studied and very comprehensive, and complicated, equations defining the properties of water as a function of these two state variables have been developed (Haar, Gallagher, and Kell 1984). For our purposes, simple relations were determined by fitting equations to data using a non-linear, least squares fitting program. The equations are given in the text, and plots are shown that illustrate the fit of the equations to the data.

The component's specific heat in the model are functions of temperature. Therefore, a feedback loop is included in the model (see Figure 9) that saves the current retort temperature, and allows it to be used in the next time step to calculate the specific heats for the next time step. Temperature variable specific heat is included in the model for water, steam, rock, and kerogen. Temperature-dependent specific heat of vaporization of water is also included. Pyrolysis is endothermic, and some heat will be consumed in the reaction. This consumption of heat for pyrolysis is not included in the model.

\subsubsection{Specific heat of water and steam}

The specific heat of water is relatively constant from 0 to about $300{ }^{\circ} \mathrm{C}$ (Figure 9). Above that temperature, it rises sharply reaching a peak at the critical point. In this model, the equation for specific heat is extrapolated to as high in temperature as needed. This is not an important issue for water as water has all boiled off to steam long before the critical point is reached. The equation used for the specific heat of water is:

$$
S_{w}=\frac{4163.773-0.02363 \cdot T^{2}}{1-7.1383 \times 10^{-6} \cdot T^{2}}
$$

where temperature is in ${ }^{\circ} \mathrm{C}$. 


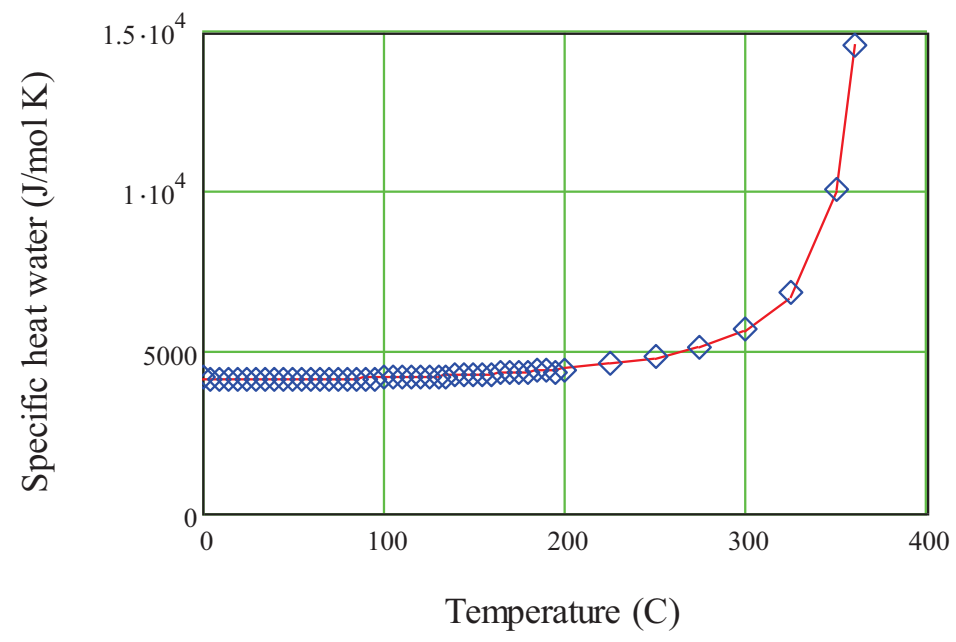

Figure 9. Specific heat of water as a function of temperature below the critical point.

The specific heat of steam increases gradually as a function of temperature. Data from the NIST chemistry web book were fit to a polynomial:

$$
S_{s t}=1831.27+0.476158 \cdot T+3.3172 \times 10^{-4} \cdot T^{2}-1.6206 \times 10^{-7} \cdot T^{3}
$$

This equation is continuous through the critical point of water, and so is used for all temperatures.

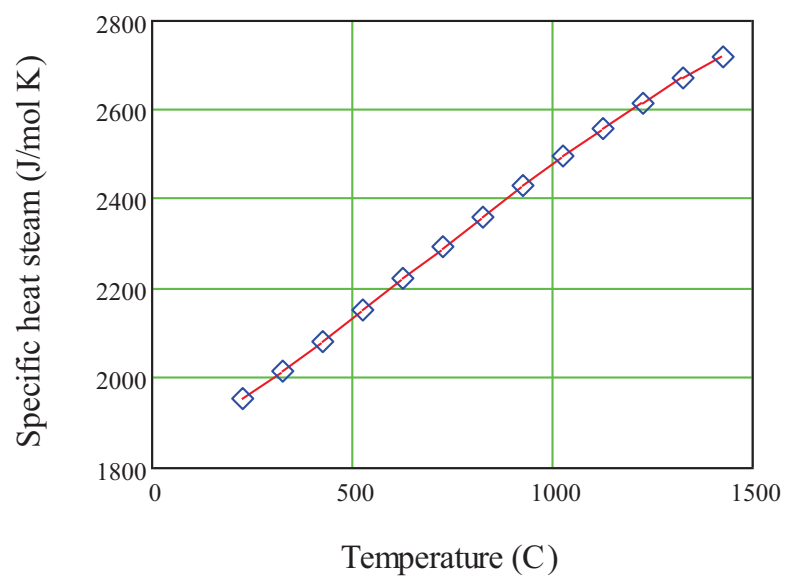

Figure 10. Specific heat of steam as a function of temperature.

The heat of vaporization of water is also a function of temperature (Figure 11). The heat of vaporization is not continuous through the critical point, as the heat of vaporization looses meaning above the critical point. As almost all phase changes between water and steam take place well below the critical point, this should not be a problem. A linear equation (dashed brown line) was fit to the heat of vaporization data below a temperature of $200{ }^{\circ} \mathrm{C}$ to prevent negative values of heat of vaporization. The polynomial used is given by:

$v_{w}=2.5 \times 10^{6}-2649.8 \cdot T$ 


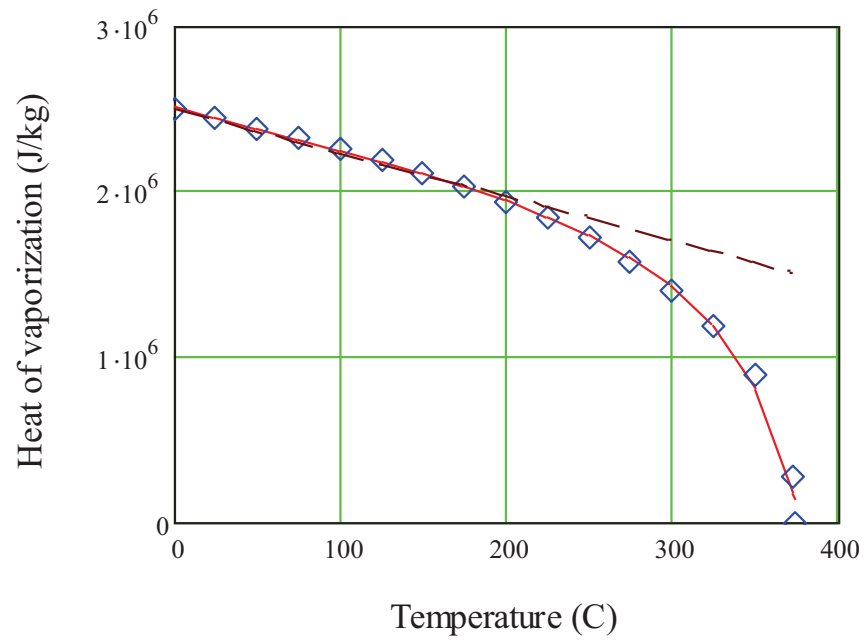

Figure 11. Heat of vaporization of water as a function of temperature.

\subsubsection{Specific heat of rocks and kerogen}

Data on the specific heat for a wide range of rocks and minerals was analyzed by Waples and Waples (2004). These authors found that the specific heat data as a function of temperature $\left({ }^{\circ} \mathrm{C}\right)$ were fit well by normalizing the data to the specific heat at $200{ }^{\circ} \mathrm{C}$. The polynomial used to fit the reduced data is plotted in Figure 12 and is given by:

$S_{r}=0.716+1.720 \times 10^{-3} \cdot T-2.13 \times 10^{-6} \cdot T^{2}+8.95 \times 10^{-10} \cdot T^{3}$

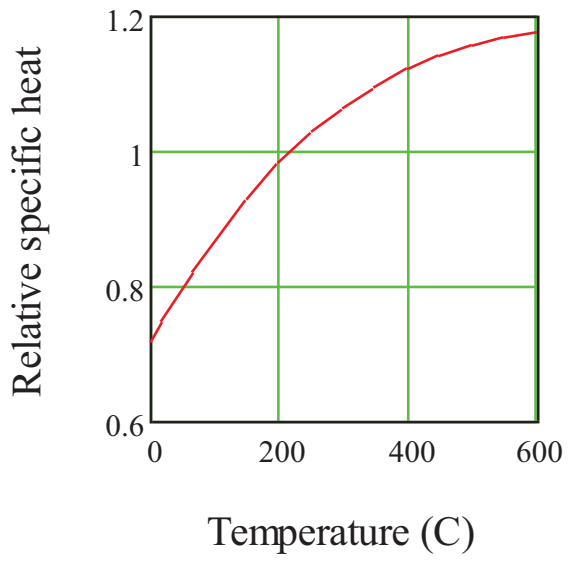

Figure 12. Reduced specific heat referenced to $200 \stackrel{\circ}{ } \mathrm{C}$ as a function of temperature.

This equation fits both the mineral matter in the Green River formation, and the kerogen content. The specific heat at $200{ }^{\circ} \mathrm{C}$ for the kerogen is $1965 \mathrm{~J} \mathrm{~kg}^{-1} \mathrm{~K}^{-1}$ and for the shale is $1113 \mathrm{~J} \mathrm{~kg}^{-1} \mathrm{~K}^{-1}$ (Waples and Waples 2004).

\subsubsection{Heat model}

The primary objective of this exercise is to quantify the energy balance for an oil shale retort. We therefore need a model for the flow of energy into the retort, between the different components within the 
retort, losses of energy to the surrounding environment, and finally, the amount of energy extracted from the retort. This balance will drive the economics of the retorting process. Heat or energy is the proper variable to use in the retorting model, not temperature. Temperature is an intensive state variable that will depend on the heat in the system, but is not a conserved component. The relation between temperature and heat is given by equation 1 .

The primary object of the heat model is a stock identified as retort heat (Figure 13). This stock contains all the heat that is present in the reservoir. This heat is distributed among a number of different phases within the reservoir, but the sum total of heat is recorded in this one stock. The units for the stock retort heat are joules $(\mathrm{J})$.

The initial condition for the amount of heat in this stock depends on the ambient temperature in the reservoir, the mass of other components in the reservoir, and the heat capacity of those components. For initial conditions, an ambient temperature was determined using the geothermal gradient of $34{ }^{\circ} \mathrm{C} \mathrm{km}^{-1}$ (Blackett 2004). From the Shell EIS, the overburden is about $330 \mathrm{~m}$ thick, and the retort zone is about 330 $\mathrm{m}$ thick. The median depth of the retort is then about $500 \mathrm{~m}$. Surface temperature is set at $8{ }^{\circ} \mathrm{C}$. This gives a retort initial temperature of about $25^{\circ} \mathrm{C}$. Using Equation 1, an initial temperature of $25^{\circ} \mathrm{C}$, the masses of other components in the retort, and the specific heat of those components at $25^{\circ} \mathrm{C}$, the initial retort heat is calculated by the model.

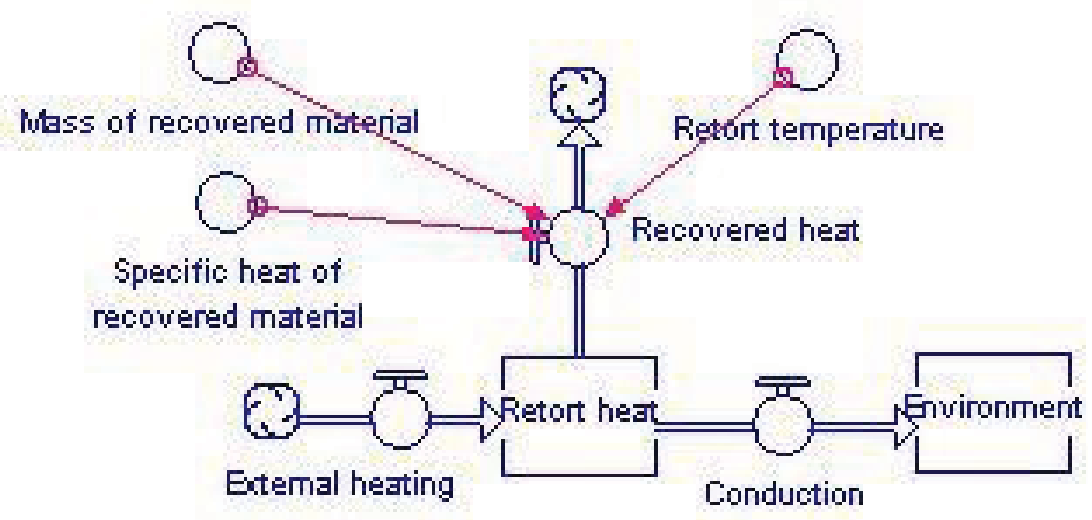

Figure 13. Heat model.

Two other stocks are included in the heat model, a stock for heat lost to the environment (i.e., the formation outside the retort), and a stock for heat recovered at the surface in produced products (steam, oil, and gas). These stocks sum the heat removed from the retort, and are initially $0 \mathrm{~J}$.

There are three flows associated with retort heat: external heating, conduction to the environment, and heat extracted to the surface. As energy flows, the units are $\mathrm{J}_{\text {day }}{ }^{-1}$. External heating represents the energy added to the retort to raise the temperature to induce pyrolysis of the kerogen. This is assumed to be a constant flux boundary condition. Two parameters are used to describe this heating; a heating rate in J day $^{-1}$, and a duration in days of total heating. The duration is used in a STEP function to turn off heating after the heating duration has elapsed. From the EGL EIS and the Shell EIS, heating durations on the order of several years are indicated. EGL provides a heating rate in their EIS of $2.1 \times 10^{11}{\mathrm{Btu} \mathrm{yr}^{-1}}^{1}$ $\left(6.1 \times 10^{11} \mathrm{~J} \mathrm{day}^{-1}\right)$. Heats of retorting are also given by EGL and by Rajeshwar et al. (1979) that give the amount of heat required to retort $1 \mathrm{~kg}$ of oil shale. These numbers range from $4.4 \times 10^{5} \mathrm{~J} \mathrm{~kg}^{-1}$ to $1.7 \times 10^{6} \mathrm{~J}$ $\mathrm{kg}^{-1}$ depending on the grade of the oil shale involved. Given some estimates of the mass of kerogen in the retort $\left(\sim 2 \times 10^{9} \mathrm{~kg}\right.$, discussed below), and the heat of retorting, the total amount of heat needed to complete the retort can be estimated to be between $4 \times 10^{14}$ and $1.6 \times 10^{15} \mathrm{~J}$. For heating rates on the order of $6 \times 10^{11} \mathrm{~J}$ 
day $^{-1}$, the heating duration ranges from 1.8 to about 7 years. These calculations give us a range of heating rates and durations to serve as a starting point for defining the energy input to the retort, and are generally consistent with estimates provided by the energy companies.

Heat added to the retort will be lost by thermal conduction to the surrounding country rock. Thermal conduction is described by Fourier's law of heat conduction:

$$
Q=-A \cdot k \cdot \frac{\Delta T}{\Delta x}
$$

where

$$
\begin{aligned}
\mathrm{Q} & =\text { heat transfer }\left(\mathrm{J}_{\text {day }}^{-1}\right) \\
\mathrm{A} & =\text { area across which heat is conducted }\left(\mathrm{m}^{2}\right) \\
\mathrm{k} & =\text { thermal conductivity }\left(\mathrm{J} \mathrm{m}^{-1} \text { day }^{-1} \mathrm{~K}^{-1}\right) \\
\Delta \mathrm{T} & =\text { temperature difference }(\mathrm{K}) \\
\Delta \mathrm{x} & =\text { distance between retort and environment }(\mathrm{m})
\end{aligned}
$$

The thermal conductivity of Green River oil shale ranges from $6 \times 10^{4}$ to $1.6 \times 10^{5} \mathrm{~J} \mathrm{~m}^{-1} \mathrm{day}^{-1} \mathrm{~K}^{-1}$ (Rajeshwar et al. 1979). From geometry of the retorts given by Shell and EGL, the surface area of the retort is calculated to be $60,000 \mathrm{~m}^{2}$. From the Shell EIS, which gives a distance of $75 \mathrm{~m}$ from the retort edge to the freeze wall, a distance to the environment is set at $75 \mathrm{~m}$. The temperature difference is calculated from the difference between the retort temperature, and the temperature of the environment, 25 ${ }^{\circ} \mathrm{C}$. This is therefore a constant temperature boundary condition. Once the retort is up to temperature, the conductive heat loss will be on the order of $1 \times 10^{10} \mathrm{~J}_{\text {day }}{ }^{-1}$. We will assume that heat conduction is in steady state at all times. This is a large simplification as there will be a significant temperature transient during heating. For this model, we assume a linear temperature drop between the retort and the environment is maintained at all times and that the distance to the constant temperature boundary conditions does not change.

Once retort operations start, steam, oil, and gas will be produced from the retort. As these components are removed from the reservoir, they will carry a certain amount of heat with them. The amount of heat extracted from the reservoir will depend on the mass extracted, the temperature of the extracted component, the specific heat of the component, and any heat consumed by phase changes. Equation 1 is used to calculate the heat extracted from the retort by removing steam, oil, and gas. For steam, an extra term is added that accounts for the heat of vaporization of the steam. No heat of reaction or vaporization is included for oil or gas. For calculation of the heat extraction, the mass of extracted components is obtained from other calculations in the model. How these masses are calculated is discussed later. The equation used to calculate the flow of heat to the surface is:

$$
Q=M_{s t} \boldsymbol{\bigotimes}_{s t} T+v_{s t} \lesseqgtr+M_{o i l} s_{o i l} T+M_{g a s} s_{g a s} T
$$

where:

$$
\begin{aligned}
& \mathrm{Q}=\text { heat flow to the surface }\left(\mathrm{J} \mathrm{day}^{-1}\right) \\
& \mathrm{M}_{\mathrm{st}}=\text { mass of steam extracted }\left(\mathrm{kg} \mathrm{day}^{-1}\right) \\
& \mathrm{M}_{\mathrm{oil}}=\text { mass of oil extracted }\left(\mathrm{kg} \mathrm{day}^{-1}\right) \\
& \mathrm{M}_{\mathrm{gas}}=\text { mass of gas extracted }\left(\mathrm{kg} \mathrm{day}^{-1}\right)
\end{aligned}
$$




$$
\begin{aligned}
& \mathrm{S}_{\text {st }}=\text { specific heat of steam }\left(\mathrm{J} \mathrm{kg}^{-1} \mathrm{~K}^{-1}\right) \\
& \mathrm{S}_{\text {oil }}=\text { specific heat of oil }\left(\mathrm{J} \mathrm{kg}^{-1} \mathrm{~K}^{-1}\right) \\
& \mathrm{S}_{\text {gas }}=\text { specific heat of gas }\left(\mathrm{J} \mathrm{kg}^{-1} \mathrm{~K}^{-1}\right) \\
& \mathrm{v}_{\mathrm{st}}=\text { heat of vaporization of steam }\left(\mathrm{J} \mathrm{kg}^{-1}\right) \\
& \mathrm{T}=\text { temperature of retort }(\mathrm{K})
\end{aligned}
$$

The heat extracted from the retort can be used on the surface in plant operations. However, no credit in the model is taken for this recovery of energy. Operations that do recover some of the heat from the retort would increase the overall efficiency of the operation.

\subsubsection{Rock model}

The rock model consists of two objects. There is a single stock that represents the mineral grains of the Green River shale formation. The second object is used to calculate the kerogen mass associated with the retort rock mass. We assume no geochemical reactions with regard to the mineral grains at the temperatures achieved by in situ retorting, so there are no changes in the rock model. The purpose of the rock model is to include the mass of inorganic solids into the calculation of the amount of heat needed to bring the reservoir to the desired temperature for pyrolysis. The mass of rock is calculated from the volume of the retort and the bulk density of Green River shale. The retort volume is calculated to be $6.37 \times 10^{5} \mathrm{~m}^{3}$. At a bulk density of $2500 \mathrm{~kg} \mathrm{~m}^{-3}$, there is a total rock mass of $1.59 \times 10^{9} \mathrm{~kg}$. There are no flows to or from this stock.

A second component of the rock model is to calculate the mass of kerogen in the retort. This mass is then passed as an initial condition to the oil model. The kerogen model takes as input the grade of the oil shale in gal ton ${ }^{-1}$, because this is the number most often used to describe how rich the formation is. The grade is determined from a Fischer assay of the oil shale. For this model, we assume the Fischer assay extracts all of the kerogen from a sample. The laboratory yield in gal ton ${ }^{-1}$ is converted to $\mathrm{m}^{3} \mathrm{~kg}^{-1}$, then multiplied by the oil density. This gives $\mathrm{kg}$ of oil generated. Not all kerogen is converted to oil, some remains as char and some is lost to gases. From the stoichiometry of the pyrolysis reaction (Campbell et al. 1980), we estimate that $69.5 \%$ of the kerogen is converted. Therefore, the $\mathrm{kg}$ of oil is divided by 0.695 to convert the oil to total kerogen. For an oil shale with a grade of $25 \mathrm{gal} \mathrm{ton}^{-1}$, the grade is $1.04 \times 10^{-4} \mathrm{~m}^{3} \mathrm{~kg}^{-1}$. Assuming an oil specific gravity of $35^{\circ} \mathrm{API}\left(850 \mathrm{~kg} \mathrm{~m}^{-3}\right)$, the kerogen content of the rock is $0.127 \mathrm{~kg}$ kerogen per $\mathrm{kg}$ of oil shale. This is a typical number from the published literature. For the total rock mass in the retort, the total kerogen is calculated to be $2.0 \times 10^{8} \mathrm{~kg}$. The expected oil yield from pyrolysis is calculated to be $1.4 \times 10^{8} \mathrm{~kg}$ or $1 \times 10^{6}$ barrels. The kerogen model takes as input the grade in gal ton ${ }^{-1}$, and calculates the $\mathrm{kg}$ of kerogen associated with the $\mathrm{kg}$ of oil shale in the retort. This is passed to the oil model as an initial condition.

\subsubsection{Water model}

The water model in the oil shale retort model is very important for the energy balance calculations. Water has very high specific heat, and the heat of vaporization of water to steam is also very high. Therefore, the heating and vaporization of water in the retort will play a very important role in heating of the retort. The water model consists of three stocks, one for water, a second for steam, and third for steam produced to the surface (Figure 15). These water and steam stocks are connected by a two directional flow representing boiling and condensation. Mass transfer through this flow will depend on the temperature and pressure of the reservoir. Connected to the steam stock is a flow from the retort to the surface that represents steam extraction. We assume no pumping of water from the retort to draw-down water in the system prior to heating. Because this activity would precede heating, it could be incorporated by changing the initial conditions in the water stock. 


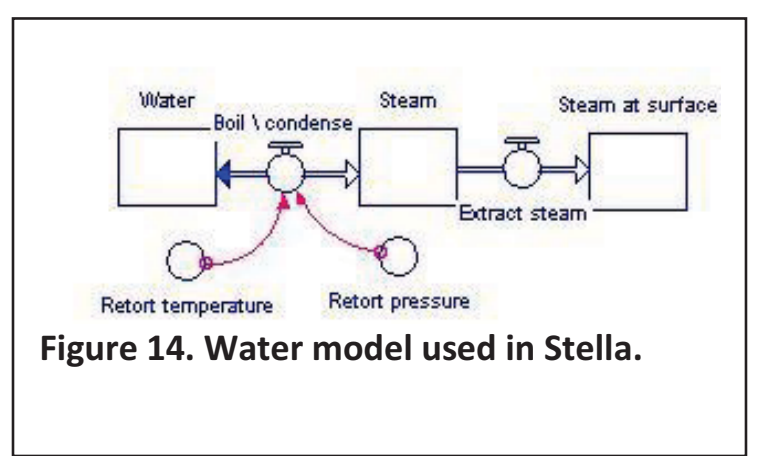

The steam stock is initially set to $0 \mathrm{~kg}$. The water stock is initialized assuming the oil shale is water saturated. The initial mass of water in the stock is calculated form the volume of the retort $\left(6.37 \times 1^{-5} \mathrm{~m}^{3}\right)$, the porosity of the retort (0.057), and the density of water (1000 $\left.\mathrm{kg} \mathrm{m}^{-3}\right)$. The initial water mass calculated in this way is $3.61 \times 10^{7} \mathrm{~kg}$. The flow that represents boiling and condensation of water is based on the pressure and temperature at which water boils or steam condenses in the retort. These calculations depend on the temperature and pressure of the retort. A very simplified model of

the thermal properties of water and steam is included in the model. We assume that the system is constrained to the water - steam equilibrium curve. Retort pressure is equal to the saturated steam - water curve plus hydrostatic pressure. When, during heating, the vapor pressure of steam exceeds the hydrostatic pressure, water begins to boil. When cooling, when the pressure drops below hydrostatic pressure, water begins to condense.

Hydrostatic pressure is calculated from the mass of water above the retort, and is given by

$$
\begin{aligned}
& \rho \mathrm{gh}=1000 \mathrm{~kg} \mathrm{~m}^{-3} * 9.8 \mathrm{~m} \mathrm{sec}^{-2} * 300 \mathrm{~m}=3000 \mathrm{kPa} \\
& \text { where } \\
& \rho=\text { density of water }\left(\mathrm{kg} \mathrm{m}^{3}\right) \\
& \mathrm{g}=\text { acceleration of gravity }\left(\mathrm{m} \mathrm{sec}^{-2}\right) \\
& \mathrm{h}=\text { depth of retort }(\mathrm{m})
\end{aligned}
$$

The equation for steam pressure $\left(\mathrm{P}_{\mathrm{v}}\right)$ in the retort in $\mathrm{kPa}$ as a function of temperature $\left({ }^{\circ} \mathrm{C}\right)$ is given by:

$P_{v}=\exp \left(\frac{-0.534487+0.72 \cdot T}{1+0.00443 \cdot T}\right)$

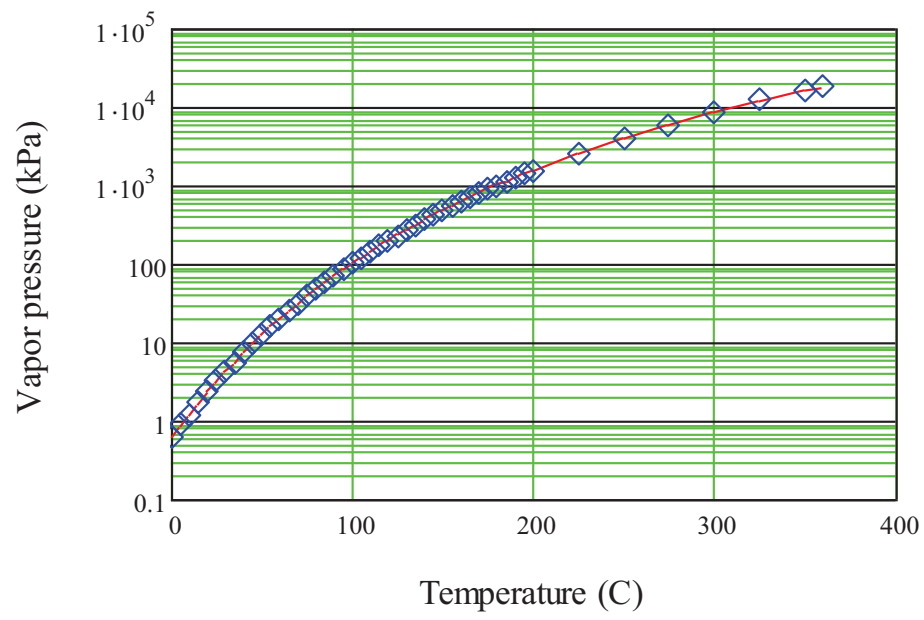

Figure 15. Vapor pressure of steam as a function of temperature used in retort model. 
We can also solve this equation to calculate the boiling temperature $\left(\mathrm{T}_{\mathrm{b}}{ }^{\circ} \mathrm{C}\right)$ of the reservoir from the hydrostatic confining pressure $\left(\mathrm{P}_{\mathrm{c}} \mathrm{kPa}\right)$ :

$$
T_{b}=\frac{7.00766+14.00823 \cdot \ln \boldsymbol{P}_{c}^{-}}{1-0.06127 \cdot \ln \left(P_{c}\right)}
$$

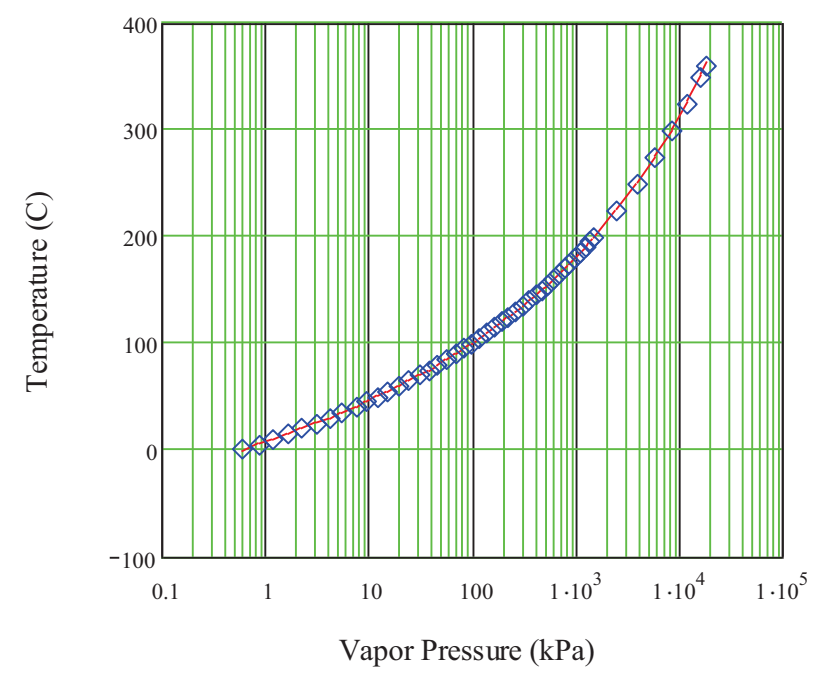

Figure 16. Function and curve to calculate boiling temperature from the hydrostatic confining pressure on the reservoir.

In the model, heat is added to the water raising the temperature. When the temperature of the retort exceeds the boiling temperature based on the hydrostatic pressure, then water begins to turn into steam. The logic of the calculation must allow for flow in both directions, that is both boiling and condensation. The equation used for the flow is:

If (confine_temp $>$ retort_temp) then

$$
M_{s \rightarrow w}=\frac{\boldsymbol{C}_{r}-T_{c} \lesseqgtr M_{s} \cdot s_{s}}{v_{s}}
$$

else

$$
M_{w \rightarrow s}=\frac{\boldsymbol{C}_{r}-T_{c} \dot{j} M_{w} \cdot s_{w}}{v_{s}}
$$

When the retort temperature either exceeds the boiling temperature or drops below the boiling temperature, there is a temperature difference that has to be corrected. Multiplying this temperature difference by the specific heat of the phase and the mass of phase defines the number of joules needed to bring the temperature back into equilibrium. Dividing by the number of joules $\mathrm{kg}^{-1}$ consumed or liberated by the phase transformation reaction, gives the mass of phase transfer needed to bring the temperature back into equilibrium. Note that $T_{r}-T_{c}$ changes sign giving positive and negative flows through this flow object. 
The final component of the water model is a flow from the steam stock to the surface that represents extraction of steam from the retort. Flow to the surface is assumed to be a function of the amount of steam with a constant fraction of the remaining steam removed per unit time. This gives the mass of steam extracted to the surface $\left(\mathrm{M}_{\mathrm{st}}\right)$ used in equation 7.

\subsubsection{Kerogen / Oil model}

Pyrolysis occurs in the absence of oxygen, so that the organic matter is broken down into less complex (shorter chain) organic molecules. Light, hydrogen-rich products are driven off, leaving behind a carbonrich char. Formation of oil occurs at temperatures between about 400 and $500^{\circ} \mathrm{C}$. Kerogen, with an initial $\mathrm{C} / \mathrm{H}$ mole ratio of about 0.67 undergoes three pyrolysis reactions (Campbell et al. 1980; Huss and Burnham 1982):

1) Primary pyrolysis occurs between 350 and $500{ }^{\circ} \mathrm{C}$, oil is driven off generating a residual char with a $\mathrm{C} / \mathrm{H}$ ratio in the range of 1 to 1.6 ;

2) Secondary char pyrolysis occurs between 500 and $650{ }^{\circ} \mathrm{C}$, hydrogen gas and methane gas are driven off, the residual char has a $\mathrm{C} / \mathrm{H}$ ratio between 1.6 and 4.3 .

3) above $650{ }^{\circ} \mathrm{C}$, hydrogen gas, ammonia, and hydrogen sulfide are driven off, leaving the char with little hydrogen.

Writing out the stoichiometry of the primary pyrolysis reaction, we get the following generalized (and much simplified) reaction for pyrolysis (Huss and Burnham 1982):

$$
\begin{aligned}
\mathrm{C}_{1} \mathrm{H}_{1.5} \mathrm{O}_{0.05} \rightarrow & 0.014 \mathrm{CO}_{2}(\mathrm{~g})+0.015 \mathrm{H}_{2}(\mathrm{~g})+0.012 \mathrm{C}_{3} \mathrm{H}_{8}(\mathrm{~g})+0.018 \mathrm{H}_{2} \mathrm{O} \\
& +0.72 \mathrm{C}_{1} \mathrm{H}_{1.7} \text { (oil) }+0.228 \mathrm{C}_{1} \mathrm{H}_{0.63} \text { (char) }
\end{aligned}
$$

Temperatures during in-situ retorting will be constrained to less than $500^{\circ} \mathrm{C}$, unless combustion is induced in the retort by introducing air. In writing this simplified reaction, we assume all $\mathrm{O}$ in carboxyl groups forms carbon dioxide, and that hydrogen is combined in hydrocarbon products with a $\mathrm{C} / \mathrm{H}$ ratio of about 0.5 representing paraffins, olefins, and naphthenes. This indicates that about $20 \%$ of the initial carbon will end up in char. Converting the reactants and products in Equation 12 back to weights, we get that for each $\mathrm{kg}$ of kerogen pyrolyzed, the yield will be $0.043 \mathrm{~kg}$ of $\mathrm{CO}_{2}(\mathrm{~g}), 0.695 \mathrm{~kg}$ of liquid hydrocarbons, $0.037 \mathrm{~kg}$ of hydrocarbon gases, and $0.202 \mathrm{~kg}$ of char. The mass of hydrocarbons, or the lengths of the hydrocarbon chains, will range from methane to much more complex molecules. This range of molecules will result in a wide range of boiling points for the reaction products. As result, there will be a mix of volatile and liquid hydrocarbons, and the mix will vary as the retort temperature varies relative to the boiling points of the hydrocarbons.

The reaction kinetics of kerogen pyrolysis have been extensively investigated (Campbell and Burnham 1980; Braun and Burnham 1986; Bar et al. 1986; Skala et al. 1990). Experimental conditions have mainly covered the very high heating rates and atmospheric pressure conditions of surface retorts. Kerogen is a complex organic molecule, and is broken down into a wide range of product molecules during pyrolysis. The composition of the products will depend on temperature, pressure, and the heating rate. Therefore, a single, or even a series, of kinetic reactions can not readily describe the kinetics of kerogen pyrolysis. Most thermogravimetric analyses of oil shale response to heating, however, indicate that kerogen breakdown occurs in a single peak around $400{ }^{\circ} \mathrm{C}$ (Figure 17). An additional reaction occurs at a temperature of about $700^{\circ} \mathrm{C}$, but this is higher than temperatures expected for in situ retorting. Because the thermal gravimetric response shows a single peak, a number of authors have used simple one component models of kerogen pyrolysis. 


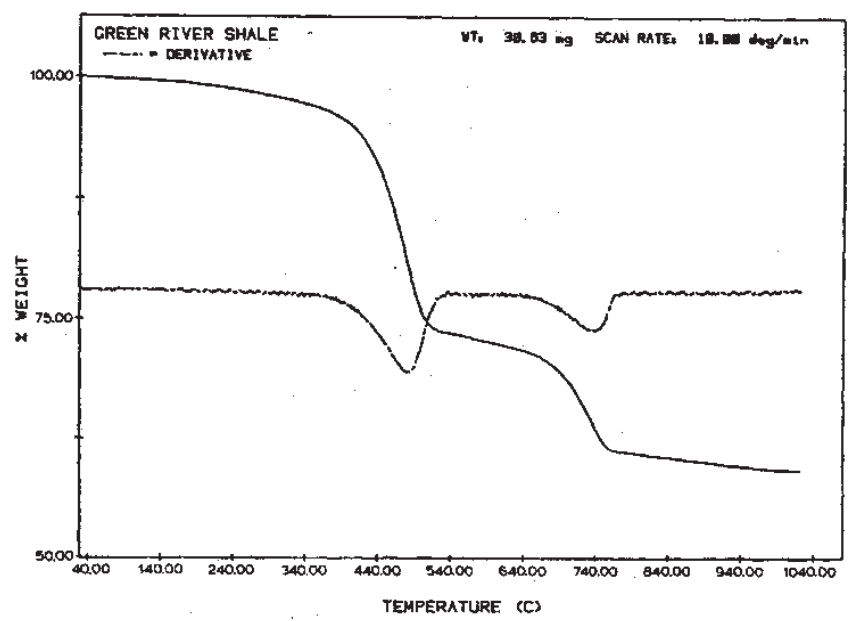

Figure 17. Thermal gravimetric and differential thermal gravimetric curves for a Green River oil shale specimen (Earnest 1982).

For systems that are too complex to be characterized in a fundamental way, it is common to describe the reaction in terms of a lumped pseudo species (Burnham and Braun 1999). A first order lumped parameter kinetic model was fit to kerogen decomposition by Campbell et al. (1978) and is adopted for this model. It is a single reaction model that describes the overall reaction of kerogen to oil. Combining this kinetic model with the stoichiometric model in equation 12, provides a means to model the retort. For a single first order pyrolysis reaction taking place under a constant heating rate $\left(\mathrm{dT} / \mathrm{dt}=\mathrm{C}_{\mathrm{r}}\right)$, the rate of product evolution is given by (Burnham and Braun 1999):

$\frac{d M}{d T}=\frac{-A_{f}}{C_{r}} \cdot \exp \left[-\frac{E_{a}}{R T}-\left(1-\frac{2 R T}{E_{a}}\right) \cdot\left(\frac{A_{f} R T^{2}}{C_{r} E_{a}}\right) \cdot \exp \left(\frac{-E_{a}}{R T}\right)\right]$

where

$\mathrm{E}_{\mathrm{a}}=$ Activation energy $\left(\mathrm{J} \mathrm{mol}^{-1}\right)$

$\mathrm{A}_{\mathrm{f}}=$ Preexponential frequency factor $\left(\right.$ day $\left.^{-1}\right)$

$\mathrm{M}=$ Mass of kerogen $(\mathrm{kg})$

$\mathrm{R}=\operatorname{Gas}$ constant $\left(\mathrm{J} \mathrm{mol}^{-1} \mathrm{~K}^{-1}\right)$

$\mathrm{T}=$ Temperature $\left({ }^{\circ} \mathrm{K}\right)$

$\mathrm{C}_{\mathrm{r}}=$ Constant heating rate $\left({ }^{\circ} \mathrm{K}\right.$ day $\left.^{-1}\right)$

$\mathrm{t}=$ time (day)

Temperature and time are related by the heating rate so that the change is mass with respect to temperature can also be related to the change in mass with respect to time.

$\frac{d M}{d t}=\frac{d M}{d T} \cdot \frac{d T}{d t}$ 
Several studies have been conducted to measure the activation energy and frequency factor for oil shale pyrolysis. These have been conducted at both constant temperature increase and at constant temperature. Results of a few of these studies are summarized in Table 1.

Table 1. Compilation of kinetic rate parameters for oil shales.

\begin{tabular}{lcc}
\hline Source Rock & $\begin{array}{c}\text { Frequency Factor } \\
\left(\text { day }^{-1}\right)\end{array}$ & $\begin{array}{c}\text { Activation energy } \\
\left(\mathrm{J} \mathrm{mol}^{-1}\right)\end{array}$ \\
\hline Spanish $^{\mathrm{a}}$ & $1.8 \times 10^{13}$ & 150 \\
Anvil Points $^{\mathrm{a}}$ & $7.3 \times 10^{20}$ & 247 \\
Clear Creek $^{\mathrm{a}}$ & $2.4 \times 10^{21}$ & 254 \\
Israel $^{\mathrm{b}}$ & $8.0 \times 10^{10}$ & 118 \\
Anvil Points $^{\mathrm{c}}$ & $2.6 \times 10^{18}$ & 220 \\
\hline
\end{tabular}

a. Torrente and Galan (2001)

b. Bar et al. (1986)

c. Campbell et al. (1978)

The temperature of maximum pyrolysis yield for kerogen falls within a narrow range of about 420 to $440{ }^{\circ} \mathrm{C}$ (Huss and Burnham 1982; Clayton et al. 1992), but only for high heating rates; on the order of $2880{ }^{\circ} \mathrm{K}$ day $^{-1}\left(2{ }^{\circ} \mathrm{C} \mathrm{min}^{-1}\right)$. At lower heating rates, the conversion of kerogen occurs at lower temperatures (Figure 18). At the lower heating rates expected for an in-situ retort, the conversion should occur at lower temperatures. Figure 18 shows that kerogen conversion can be expected to happen relatively quickly once temperatures reach the vicinity of $400{ }^{\circ} \mathrm{C}$.

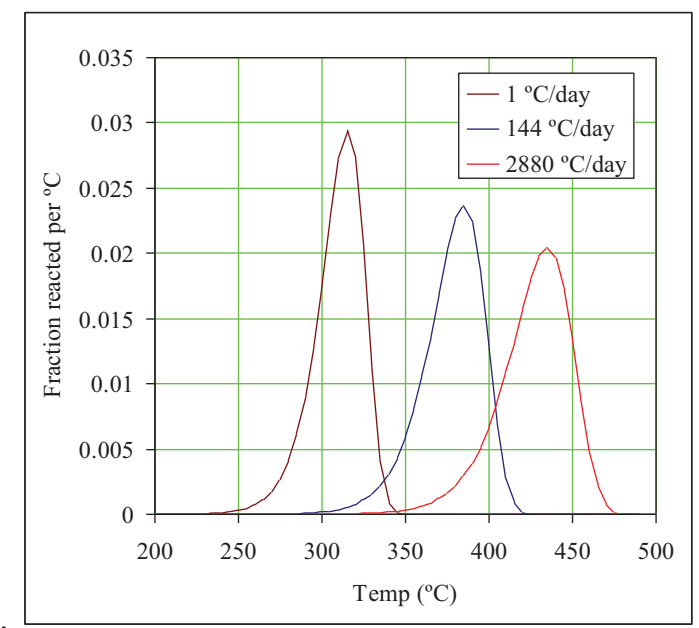

Figure 18. Mass reaction rate of kerogen as a function of retort temperature at different heating rates. Highest rates are representative of surface retorts. Lowest rate is more representative of in situ heating rates.

Surface retorting takes place at atmospheric pressures, so little work has been done on the effects of pressure on kerogen conversion. Burnham and Singleton (1983) investigated pyrolysis of Green River oil 
shale at pressures to $2.74 \mathrm{MPa}$ (Figure 19). The experiments were kinetic experiments carried out at constant heating rate. They found a small decrease in oil yield with increasing pressure for the same heating rate. There are insufficient data to parameterize a pressure effect on pyrolysis of oil shale, so pressure was not included in the Stella model.

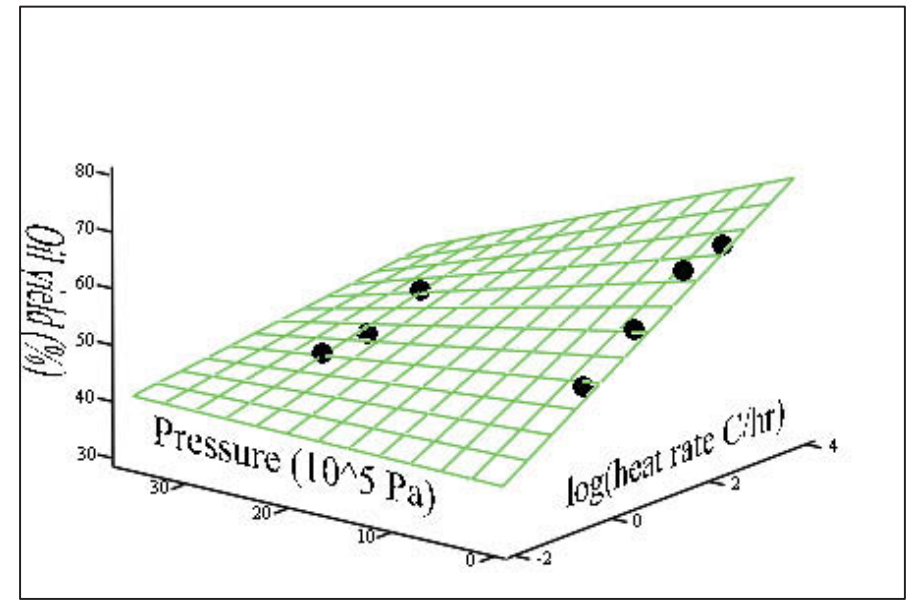

Figure 19. Effect of heating rate and pressure on oil yield (Burnham and Singleton 1983).

The kinetic model used to simulate kerogen pyrolysis is given by:

$\Delta M=M_{t-1} A_{f} \cdot \exp \left(\frac{-E_{a}}{R \cdot T}\right) \cdot \Delta t$

The oil model calculates the mass of kerogen pyrolyzed in a time step using equation 15 , then uses the mass fractions of products calculated from equation 12 to distribute mass to the product stocks (Figure 20).

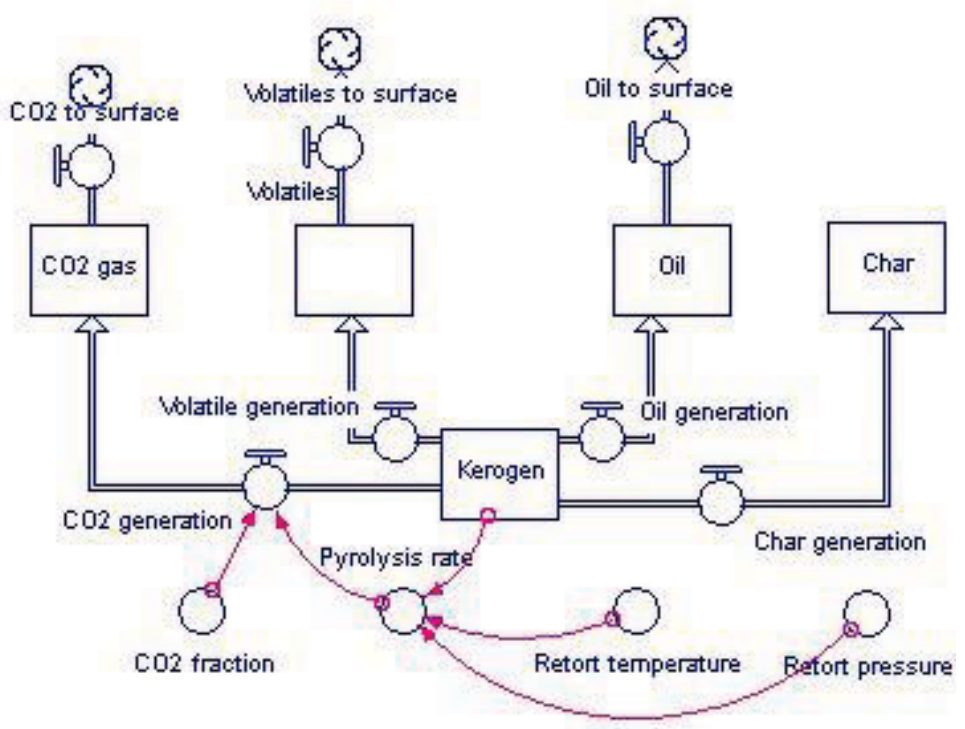

Figure 20. Model used to calculate the pyrolysis of kerogen to products in the retort. Calculation of flows is illustrated for $\mathrm{CO}_{2}$. The other flows are calculated in the same fashion.

The initial kerogen content is calculated from the oil shale grade in the rock model. The other stocks are set to 0 as an initial condition. 


\subsubsection{Converters and Accumulators}

There are a number of accumulators that keep track of the total masses of components extracted at the land surface. The amount of energy recovered in joules is calculated from the mass of oil and gas extracted at the surface. The Carbon Trust gives an energy content of oil of $12,751 \mathrm{~kW} \mathrm{hr}$ ton $^{-1}$. This converts to a conversion factor of $4.6 \times 10^{7} \mathrm{~J} \mathrm{~kg}^{-1}$ for liquid hydrocarbons. For hydrocarbon gas, the energy content is $11 \mathrm{~kW} \mathrm{hr} \mathrm{m}^{-3}$ according to the Carbon Trust. Because we generate $\mathrm{kg}$ of gas, the volumetric energy content must be converted to a mass based energy content. We assume that the gas is methane with a mass of $10 \mathrm{~g} \mathrm{~mol}^{-1}$ and use the ideal gas law to convert a volume of gas to $\mathrm{kg}$ of gas. The energy content of the gas hydrocarbons is calculated to be $9.7 \times 10^{7} \mathrm{~J} \mathrm{~kg}^{-1}$.

The model also accumulates carbon dioxide at the surface so that the generation of greenhouse gases from in situ retorting can be evaluated.

The model was run using a 1-day time step for a period of 4,000 days. The Runge-Kutta 4 integration method was used. A time step of 5 days gave results that differed by $0.2 \%$ from the 1 -day time step. A time step of 0.5 days gave the same results as the 1-day time step. One day was selected for modeling runs.

\subsubsection{Base Case Results}

The model was simulated using the parameters discussed above. The grade of the oil shale was set at 25 gal ton $^{-1}$. As heat is added to the retort, the pressure and temperature increase until the vapor pressure of steam exceeds the confining hydrostatic pressure. This occurs at a temperature of $232{ }^{\circ} \mathrm{C}$ at 860 days (Figure 21). The temperature profile flattens while boiling occurs as heat added to the retort is consumed by boiling. The pressure increases during boiling, and so the boiling temperature increases slightly and is not constant as it would be for atmospheric conditions.

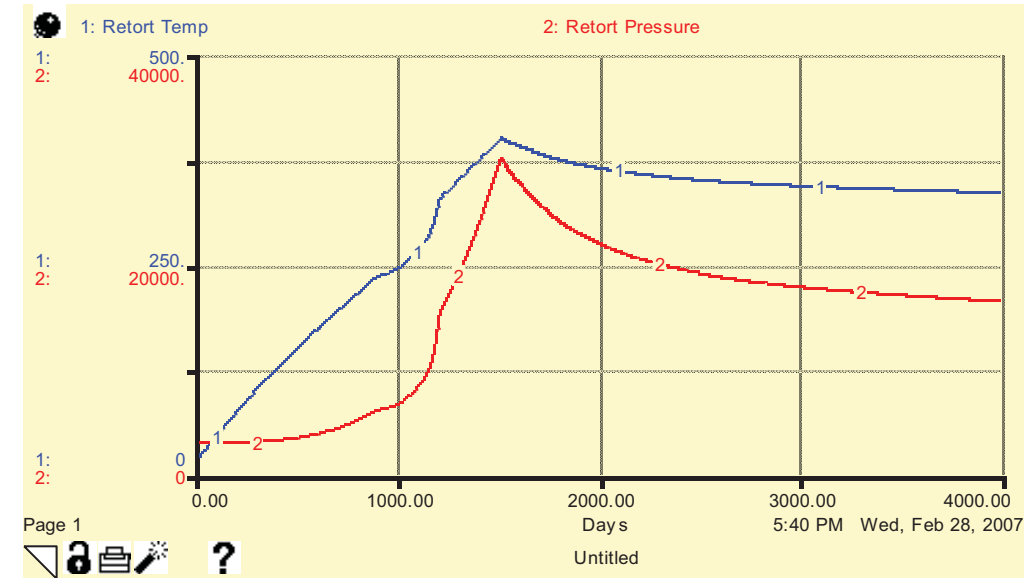

Figure 21. Increase in temperature and pressure with heating of the retort.

The rate of kerogen pyrolysis reaches a critical point at about 1100 days (Figure 22) and kerogen is rapidly converted to products. This rate of conversion is based on very small scale laboratory experiments, and may not be realistic for application to retort scale simulation. Measurements of the frequency factor and activation energy for the kerogen pyrolysis reaction show a wide range of values (Table 1), so there may be some uncertainty in this transformation rate. The laboratory rates predict complete conversion of the kerogen in about 200 days. Gas volatiles in the model are extracted rapidly and have been recovered at the surface by 1550 days. 


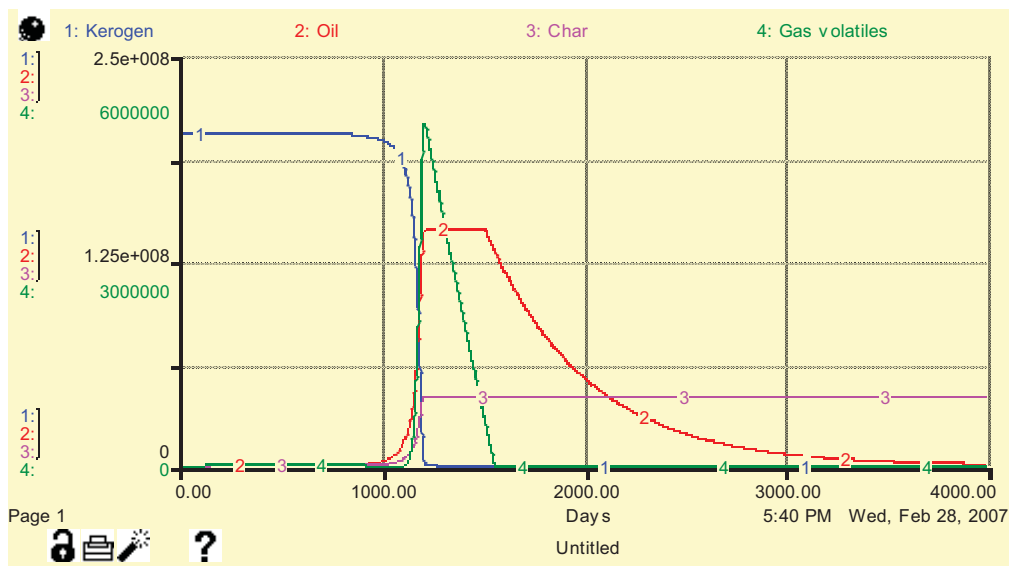

Figure 22. Distribution of kerogen and kerogen pyrolysis products as a function of time.

Most of the heat added to the retort goes to heating up the rock matrix (Figure 23). Water and kerogen also heat up. At day 860, boiling of the water releases all the energy contained in water and transfers the energy to steam. There is more energy in the steam than in the water because the steam contains the heat of vaporization. About day 1100, the heat in kerogen is released as kerogen is pyrolyzed to gas and liquid hydrocarbons. As soon as the retort temperature rises above ambient, conduction to the surrounding environment serves as a heat loss. When heating stops on day 1500 , heat in the retort begins to decline by conduction to the environment.

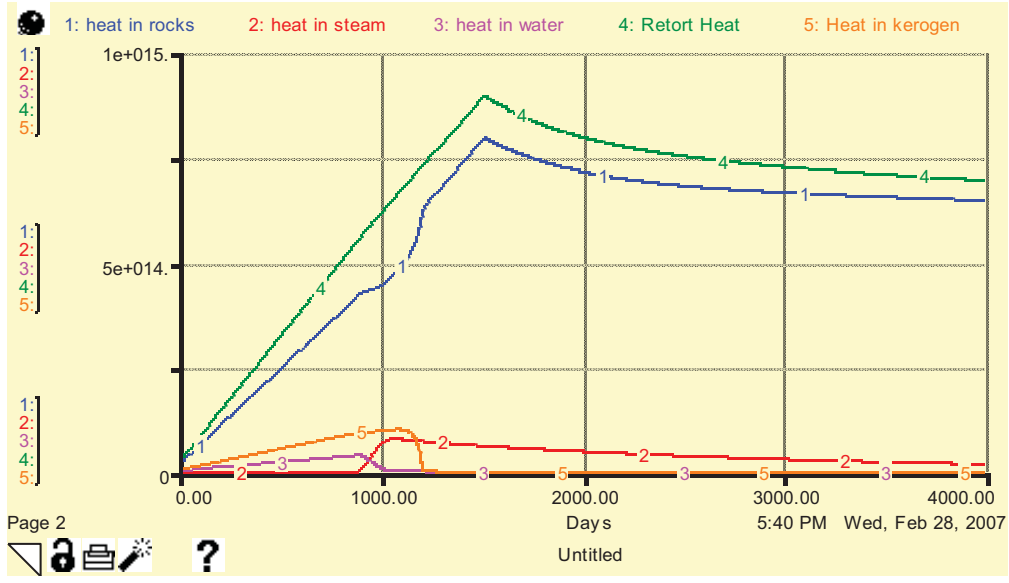

Figure 23. Distribution of energy (heat) in the retort during the first 1500 days.

The simulation indicates that the in-situ retorting produces much more energy than consumed to drive the pyrolysis reaction (Figure 24). A total of $9.4 \times 10^{14}$ joules of energy are needed to bring the retort up to 400 ${ }^{\circ} \mathrm{C}$. The energy contained in the oil and gas withdrawn from the retort amounts to $7.3 \times 10^{15}$ joules, or about 8 times the energy expended. Oil recovered from the retort (Figure 25) are 1.0x $10^{6}$ barrels. Based on the initial estimate of 25 gal ton- ${ }^{1}$ as the grade of oil shale, the predicted recovery is $1.05 \times 10^{6}$ barrels. To recover 1 million barrels of oil, 8700 tonnes of carbon dioxide are generated. This oil recovery is probably optimistic. There are only about 7400 barrels of oil left in the retort. It is unlikely that the oil would drain from the pores so completely. The factor of 8 energy recovery factor is probably optimistic by a factor of 2 . This would suggest that something like 500,000 barrels of oil could be recovered from this retort. 


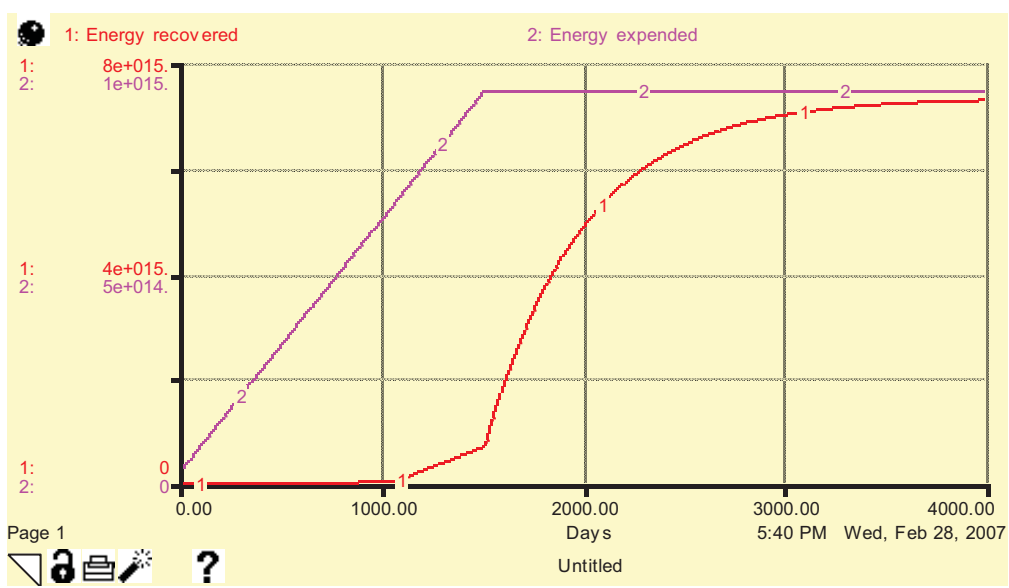

Figure 24. Energy expended and energy recovered from the retort (joules).

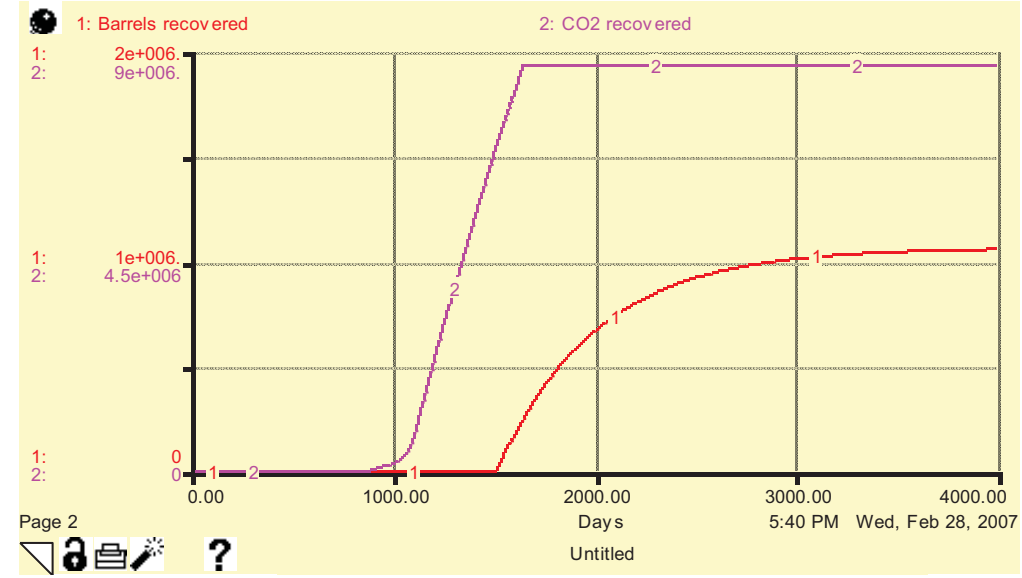

Figure 25. Barrels of oil and $\mathrm{kg}$ of $\mathrm{CO} 2$ recovered from the retort.

\subsubsection{Sensitivity studies}

Evaluating the parameters in the model that have the most uncertainty leads to identification of the following parameters:

- The rate of kerogen conversion

- Initial water content

- Heat conduction out of the retort

A wide range of kinetic parameters are reported in the literature. If the rate of conversion is much slower than predicted, then the heating time may not be sufficient to convert all of the kerogen to oil. The longer the heating time, the more energy needed to start the reaction. The frequency factor and activation energy cannot be varied independently. Therefore, values for the two Anvil Points samples shown in Table 1 were simulated. The base case was the Anvil Point values from Campbell et al. (1978). It turns out that the number of barrels recovered is not very sensitive to the reaction kinetics over a wide range of values. As can be seen from Figure 22, the pyrolysis reaction is very rapid. Slowing the reaction to some extent delays the conversion a little bit, but does not prevent conversion. Only when extreme values are used for 
the kinetic parameters does the reaction rate slow to the point that conversion is not complete. Therefore, kinetic factors are not likely to be an important consideration for in situ retorting.

The initial water content can increase the heat capacity of the retort, diverting heat from the raising the temperature, and impacting the conversion of kerogen. The water content of the retort was doubled. This may have the effect of including water bound to minerals, which will be driven off the minerals when boiling occurs, and so does need to be included in the water model. When this simulation is run, the peak retort temperature drops, and the amount of heat bound up in steam increases. However, the temperature drops only to $367^{\circ} \mathrm{C}$ from about $400{ }^{\circ} \mathrm{C}$. The pyrolysis reaction is still fast enough to convert all the kerogen to oil, and the oil yield is relatively unaffected.

The final simulation evaluates heat conduction out of the retort. Thermal conductivity for oil shale reported by Rejeshwar et al. (1979) range from $6 \times 10^{4}$ to $1.5 \times 10^{5} \mathrm{~J} \mathrm{~m}^{-1} \mathrm{day}^{-1} \mathrm{~K}^{-1}$. The base case uses the lower number; the upper number would allow more heat to be lost to the surrounding rocks. When a thermal conductivity of $1.6 \times 10^{5} \mathrm{~J} \mathrm{~m}^{-1}$ day $^{-1}{ }^{\mathrm{o}} \mathrm{K}^{-1}$ is used, the retort takes longer to heat up. The retort still hits a maximum temperature of $393^{\circ} \mathrm{C}$, which is sufficient to drive pyrolysis, but it doesn't reach this temperature until day 1492. Pyrolysis occurs about day 1180 versus day 1100 under the base case. This is not significant. Oil generation does occur somewhat later, but there is generally complete conversion of the kerogen.

\subsubsection{Operation summary}

The above analysis is necessary to determine the approximate length of time needed to operate the retort and remove the gas and oil products. Over this time, a small amount of water is produced via the kerogen conversion during heating (Equation 12). Most of the produced water is from the conversion of water entrapped in the isolated pores (and residual water in effective pores) as steam. A small amount of water consumption would be necessary during daily operations. Water used for cooling of surface equipment is not included in these calculations. The operation time is also used to establish the beginning of the site remediation stage.

\subsection{Remediation Phase}

Once the operation stage is completed, the site must be remediated. As part of this remediation effort, the retort zone may be flushed with water to remove excess heat and mobile contaminants. A calculation was performed to examine the number of pore volumes of water injected into an expired retort to evaluate the cooling rate due to the heat extraction of the injected water. Input water was assumed to be $25^{\circ} \mathrm{C}$ and the system was assumed to be a well mixed reactor. The final porosity was assumed to be $10 \%$ and therefore a pore volume is equilvent to $10 \%$ of the total volume. During the first few injected pore volumes heat is removed from the reservoir via heating of the water to its boiling point, vaporization of the water, and heating the steam to the retort temperature. Within 3 pore volumes, the temperature drops from $350^{\circ} \mathrm{C}$ to $100^{\circ} \mathrm{C}$. Below this temperature, the rate of cooling significantly decreases because the only heat removal mechanism is the sensible heating of the water injected water. At this time, each pore volume of injected water will decrease the retort temperature approximately $5^{\circ}$ to $10^{\circ} \mathrm{C}$ (depending on the initial retort temperature) and ambient temperature is achieved in less than 10 pore volumes. Although these calculations do not take into account actual transport or pressure changes within the retort, it does provide enough information to suggest that the flushing to reduce contaminant concentrations will determine the number of pore volumes that need to be flushed through the system. 


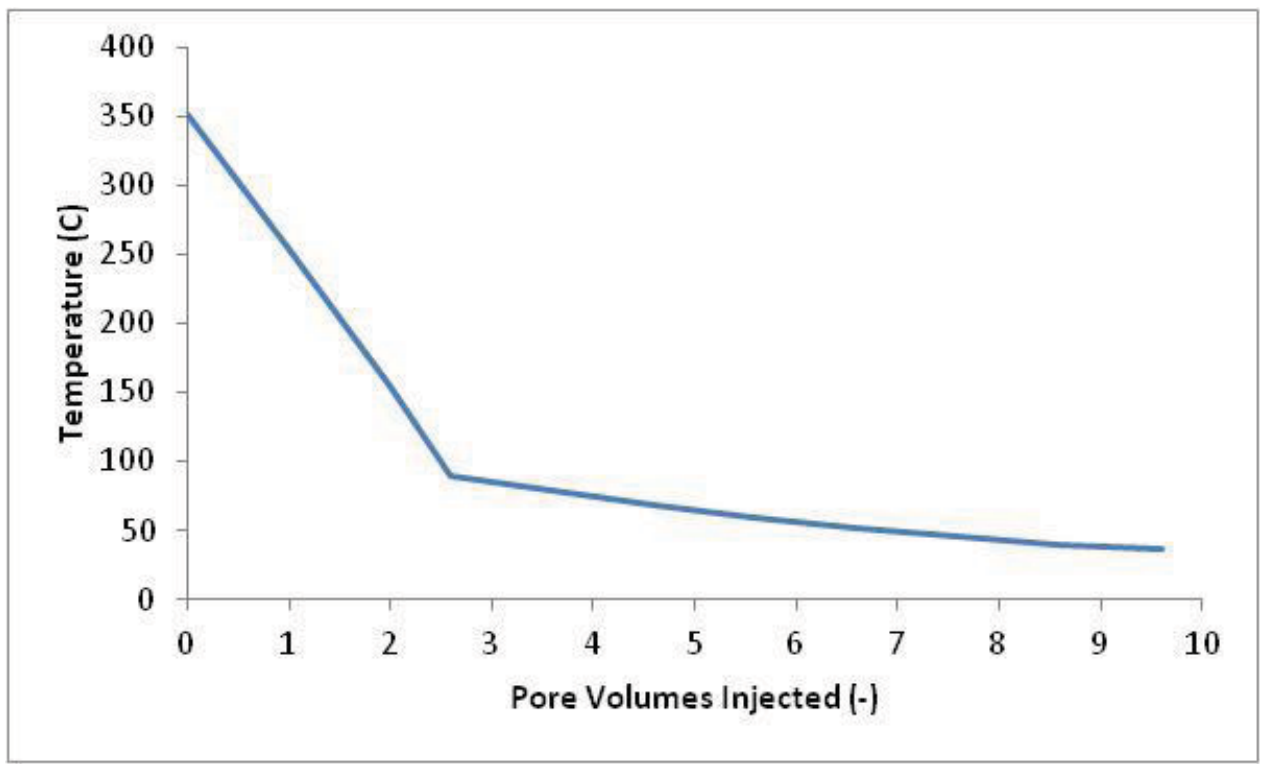

Figure 26. Retort cooling as a function of injected pore volumes.

Modeling results for Shell's Oil Shale Test Project (Shell, 2006) suggest that a 20 pore volume flush will be necessary for reduce contaminants down to an acceptable level. In their simulations they thought this would be achievable in 2 years of flushing. We used a similar approach for the remediation phase in the system dynamic model. Since flushing of contaminants takes more pore volumes than the cooling of the retort, we will assume that 20 pore volumes is the volume of water that needs to be handled. We will also assume that the water will be treated at the surface and reused during subsequent flushes.

Figure 27 illustrates the system dynamic module for the remediation system. The total remediation water required is a function of the total porosity, retort volume and the required number of pore volumes needed to be flushed through the system. The total porosity is a user defined value typically higher than the initial effective porosity, due to the removal of kerogen during the retort process. The actual water needed is less than the total remediation water required due to recycling of the water. The first pore volume is needed to refill the retort volume with water. After that initial filling, water will be recycled from the injection wells to the production wells and any water losses will be accounted for in the recycle water percentage. At this time the recycle water percent is set as a constant, and would account for water loss through the freeze wall, and makeup water needed for the water treatment on the surface.

The time necessary to complete the remediation is determined by the injection rate and the total amount of water required. We used a one dimensional form of Darcy's Law to describe the injection rate. The area was determined from retort length parameters. The hydraulic conductivity was from the initial site information that can be multiplied by a factor to account for any increases in the hydraulic conductivity due to the retorting process. The pressure gradient is currently based on the lithostatic pressure (via the overburden depth) and $1 / 10^{\text {th }}$ the width of the site. These values are used to calculate the time to pump 20 pore volumes of water and to develop the water requirement values as a function of time. 


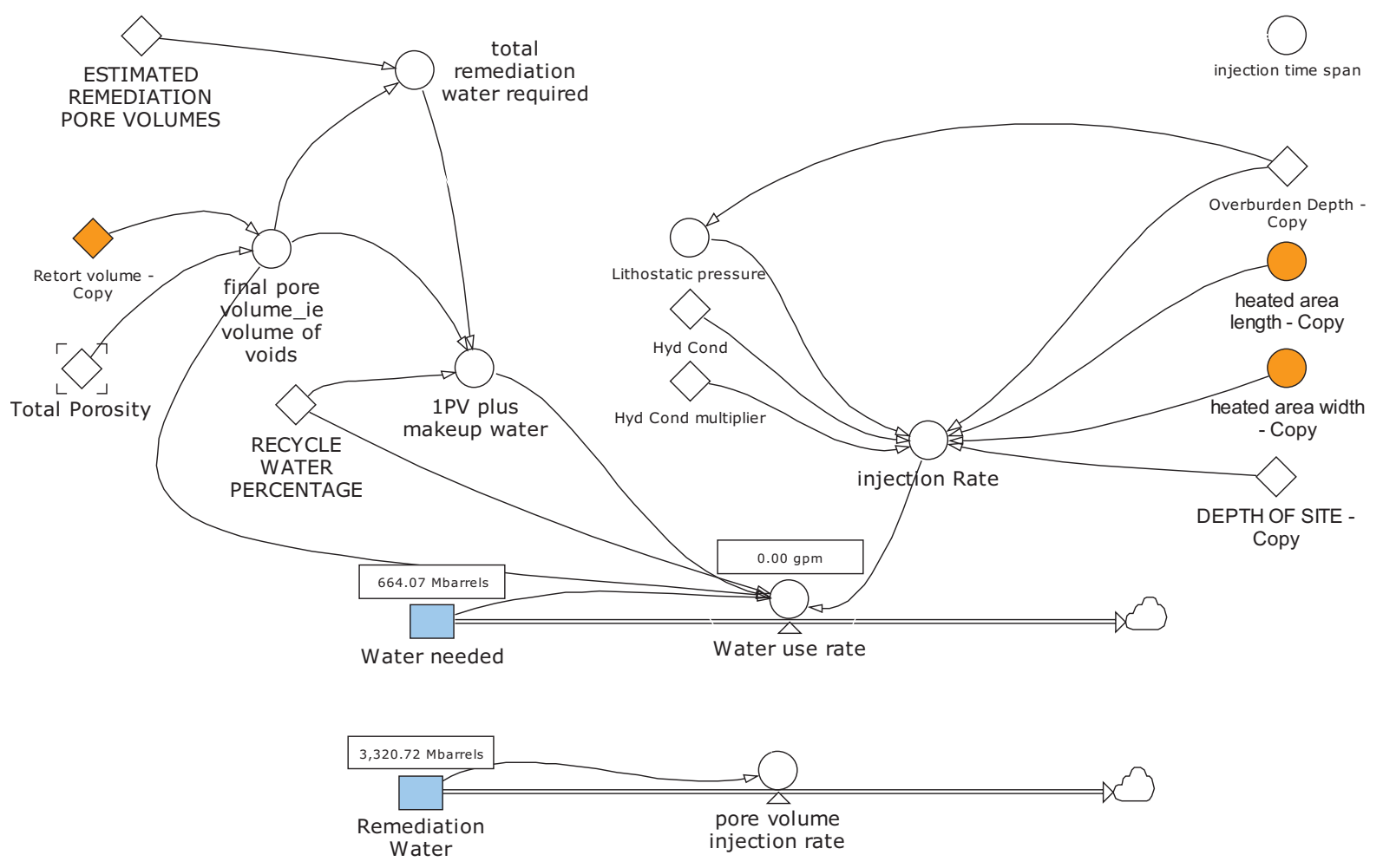

Figure 27. Remediation of the retort through subsurface flushing.

\section{Summary}

A system dynamic model was construction to evaluate the water balance for in-situ oil shale conversion. The model is based on a systems dynamics approach and uses the Powersim Studio 9 ${ }^{\mathrm{TM}}$ software package. Three phases of an insitu retort were consider; a construction phase primarily accounts for water needed for drilling and water produced during dewatering, an operation phase includes the production of water from the retorting process, and a remediation phase water to remove heat and solutes from the subsurface as well as return the ground surface to its natural state. Throughout these three phases, the water is consumed and produced. Consumption is account for through the drill process, dust control, returning the ground water to its initial level and make up water losses during the remedial flushing of the retort zone. Production of water is through the dewatering of the retort zone, and during chemical pyrolysis reaction of the kerogen conversion. 